bioRxiv preprint doi: https://doi.org/10.1101/2021.10.06.463375; this version posted October 6, 2021. The copyright holder for this preprint (which was not certified by peer review) is the author/funder, who has granted bioRxiv a license to display the preprint in perpetuity. It is made available under aCC-BY 4.0 International license.

\title{
In situ structures of membrane-assisted assembly and selective autophagy of enteroviruses
}

Selma Dahmane ${ }^{1,2,3}$, Adeline Kerviel ${ }^{4}$, Dustin R. Morado ${ }^{5}$, Kasturika Shankar ${ }^{1,2,3}$, Björn Ahlman ${ }^{1,2,3}$, Michael Lazarou ${ }^{6}$, Nihal Altan-Bonnet ${ }^{4}$, Lars-Anders Carlson ${ }^{1,2,3,{ }^{*}}$

${ }^{1}$ Department of Medical Biochemistry and Biophysics, Umeå University, Umeå, Sweden.

${ }^{2}$ Wallenberg Centre for Molecular Medicine, Umeå University, Umeå, Sweden.

${ }^{3}$ Molecular Infection Medicine Sweden, Umeå University, Umeå, Sweden.

${ }^{4}$ Laboratory of Host-Pathogen Dynamics, National Heart Lung and Blood Institute, National Institutes of Health, Bethesda, MD, USA.

${ }^{5}$ Department of Biochemistry and Biophysics, Science for Life Laboratory, Stockholm University, Stockholm, Sweden.

${ }^{6}$ Department of Biochemistry and Molecular Biology, Biomedicine Discovery Institute, Monash University, Melbourne, Australia.

*correspondence: lars-anders.carlson@umu.se

\section{Summary}

Enteroviruses are non-enveloped positive-sense RNA viruses that cause diverse diseases in humans. Their rapid multiplication depends on remodeling of cytoplasmic membranes for viral genome replication. New virions are thought to be assembled near the genome replication sites and are released in vesicles through secretory autophagy. Here, we use cryo-electron tomography to show that poliovirus assembles directly on replication membranes. Assembly progression beyond a membrane-bound half-capsid intermediate requires the host lipid kinase VPS34, whereas inhibition of ULK1, the initiator of canonical autophagy, leads to accumulation of virions in vast intracellular arrays followed by an increased release at later time points. We further identify multiple layers of selectivity in virus-induced autophagy, with a strong selection for RNA-loaded virions over empty capsids and the segregation of virions from a second class of autophagic membranes containing protein filaments bundles. These findings provide an integrated structural framework for multiple stages of the poliovirus life cycle.

\section{Keywords}

enterovirus, poliovirus, autophagy, cryo-EM, cryo-electron tomography, egress 
bioRxiv preprint doi: https://doi.org/10.1101/2021.10.06.463375; this version posted October 6,2021 . The copyright holder for this preprint (which was not certified by peer review) is the author/funder, who has granted bioRxiv a license to display the preprint in perpetuity. It is made available under aCC-BY 4.0 International license.

\section{Introduction}

Enteroviruses are a major genus of positive-sense RNA viruses within the Picornaviridae family. They include poliovirus, Coxsackieviruses and rhinoviruses and are thus responsible for a wide variety of human diseases such as poliomyelitis (poliovirus), related acute flaccid myelitis conditions (e.g. EV-D68), gastroenteritis, and viral myocarditis (Coxsackieviruses). The enterovirus particle is a non-enveloped quasi $\mathrm{T}=3$ particle of $\sim 30 \mathrm{~nm}$ diameter, encapsidating a single-stranded RNA genome of about 7500 nucleotides.

Upon infection, enteroviruses rapidly remodel cytoplasmic membranes to form a platform for viral RNA replication (Jackson, 2014; Romero-Brey and Bartenschlager, 2014; van der Linden et al., 2015). Membrane localization increases the local concentration of viral and host replication factors, which may increase the rate of replication and may additionally serve to shield the double-stranded RNA intermediate from innate immune sensing. The first stage of enteroviral membrane remodeling consists of a rapid disassembly of the secretory pathway, in particular the Golgi apparatus as seen by dispersion of Golgi marker proteins throughout the cytoplasm (Hsu et al., 2010). Resin-embedding electron microscopy has described a progression of membrane shapes with single-membrane tubes and vesicles appearing at early time points (typically $3-5 \mathrm{~h}$ post infection) and then being replaced by double-membrane structures at later time points (6-8 h p.i.) (Limpens et al., 2011). This progression of membrane topologies is paralleled by biochemical processes in the infected cell. At early time points, the viral protein $3 \mathrm{~A}$ recruits host proteins to replication membranes including the phosphatidylinositol 4-kinase beta (PI4KB) (Xiao et al., 2017). The production of PI(4)P on these membranes has been shown to aid the recruitment of the viral RNA-dependent RNA polymerase $3 \mathrm{D}^{\mathrm{pol}}$ as well as to support replication through the host-cell $\mathrm{PI}(4) \mathrm{P}$-cholesterol exchange mechanisms (Hsu et al., 2010; Roulin et al., 2014). The late-stage formation of double-membrane structures is biochemically characterized by the lipidation of host proteins belonging to the LC3 subfamily of ATG8s, a hallmark of the autophagy pathway (Taylor and Kirkegaard, 2007). Induction of autophagy in infected cells is mediated by the viral protein 2BC and is independent of the initiators of canonical autophagy, the ULK1/ULK2 protein kinases (Corona Velazquez et al., 2018; Taylor and Kirkegaard, 2007).

A paradigm shift in picornavirus replication was the observation that these inherently nonenveloped virions, which were previously thought to egress through cell lysis, can leave cells in a non-lytic manner as groups of virions contained in lipid vesicles (Bou et al., 2019; Chen et al., 2015; Feng et al., 2013; Robinson et al., 2014). Enterovirus-containing vesicles are positive for LC3 (Mutsafi and Altan-Bonnet, 2018). Autophagy in uninfected cells is increasingly recognized to be a strongly selective pathway, with a plethora of autophagy receptors mediating selection of cargo (Gatica et al., 2018). However, there is no in situ structural data on autophagosome formation or content selection. In virus-infected cells, it is not known if any selectivity is involved in the virion packaging into autophagosomes.

Whereas viral RNA replication is firmly established to take place on cytoplasmic membranes (Wolff et al., 2020b), little is known about the site of enterovirus capsid assembly and RNA loading. Preferential interaction sites between the viral capsid proteins and viral genomic RNA have been recently identified (Chandler-Bostock et al., 2020), but extensive searches have failed to identify a defined packaging signal, i.e. a sequence sufficient for RNA loading into capsids (Jiang et al., 2014). This suggests that virion assembly may need to take place in immediate vicinity of RNA production sites to ensure specific RNA encapsidation. This hypothesis is supported by the finding that an interaction between the viral membrane-bound helicase $2 \mathrm{C}$ and the capsid protein VP3 is necessary for RNA loading of enteroviruses (Jiang et al., 2014; Liu et al., 2010).

To reveal the coordination of RNA replication, virion assembly and their packaging into autophagosomes, in situ structural information is ultimately needed. Recent advances in focused-ion-beam milling and cryo-electron tomography (Turk and Baumeister, 2020) have opened up a route to obtaining such three-dimensional structural information inside infected 
bioRxiv preprint doi: https://doi.org/10.1101/2021.10.06.463375; this version posted October 6,2021 . The copyright holder for this preprint (which was not certified by peer review) is the author/funder, who has granted bioRxiv a license to display the preprint in perpetuity. It is made available under aCC-BY 4.0 International license.

cells at macromolecular resolution (Hagen et al., 2015; Klein et al., 2020; Wolff et al., 2020a; Zila et al., 2021).

Here, we present an in situ structural study of poliovirus replication, assembly, and autophagosome packaging in human cells by cryo-electron tomography. Our data reveal a membrane-bound half-capsid as a prominent virion assembly intermediate. Assembly progression past this intermediate depends on the phosphatidylinositol 3-kinase (PI3K) class III kinase VPS34, a key autophagy factor. We further show that RNA loading correlates with capsid tethering to single-membrane structures as well as to the outside of double-membrane autophagy-like structures. Finally, cryo-electron tomograms reveal a striking degree of selectivity during virus-induced autophagy, with exclusive packaging of RNA-loaded virions, and a segregation of virions from a second class of autophagy membranes containing bundles of protein filaments.

\section{Results}

\section{Cryo-electron tomography of poliovirus replication sites allows visualization of different capsid states tethered to replication membranes.}

In order to investigate the in situ structural context of enterovirus replication, cells were grown on EM grids and infected with poliovirus (type 1). Grids were plunge frozen, cryo-lamellas prepared through focused-ion-beam milling, and cryo-electron tomograms of cytoplasm were acquired (Figure S1). At 6 hours post-infection (h p.i.), infected cell tomograms revealed a starkly remodeled cytoplasm compared to uninfected cells (Fig. 1A-B compared to Fig. S2A$\mathrm{B})$. To characterize the progression of this remodeling, membrane structures were counted in multiple tomograms acquired at 3 and $6 \mathrm{~h}$ p.i. (Fig. 1C-E, Table S2). At $3 \mathrm{~h}$ p.i., singlemembranes (SMs), vesicles and tubules, were mainly observed (Fig. S2C). From 3 to $6 \mathrm{~h} \mathrm{p.i.}$ there was a significant increase in double-membrane structures, both open cup-shaped structures resembling phagophores (Fig. 1D) and closed double-membrane vesicles (DMVs, Fig. 1E). These membranes, which have been reported as being characteristic of late-stage enterovirus infection, will henceforth collectively be referred to as autophagy-like membranes (ALMs).

In addition to various membrane topologies, the cryo-electron tomograms revealed a rich level of macromolecular detail. Single-membrane tubes and vesicles contained luminal densities of relatively homogeneous appearance, not distinguishable from the cytoplasmic contents. On the other hand, ALMs had much more heterogeneous contents, including assembled virus particles, dense granules (Fig. 1B) and other contents. The tomograms clearly distinguished empty capsids from RNA-loaded ones, at both $3 \mathrm{~h}$ p.i. (Fig. 1F-G) and 6 h p.i. (Fig. 1A-B). At $6 \mathrm{~h}$ p.i. their cytoplasmic concentration was on average 7 and 10 times higher, respectively, as measured by an unbiased template matching procedure (Fig. $1 \mathrm{H})$.

We occasionally observed macromolecular complexes connecting membranes: single membranes structures connected to one another (Fig. S2D-E); single-membranes connected to ALMs (Fig. S2F), and ALMs connected to one another (Fig. S2G). More striking, however, was the frequent tethering of both empty and RNA-loaded virions to membranes through macromolecular complexes (Fig. 1A-B, F-G, yellow arrowheads). The tether appears to have a defined size and keeps the virions at a regular distance from the membrane. At $6 \mathrm{~h}$ p.i., virions were tethered to both SMs and ALMs, and the fraction of empty vs. RNA-loaded virions was similar on both types of membranes (Fig. 1I). Strikingly, virions were only tethered to the outer face of ALMs, whereas engulfed virions had lost the tether (Fig. 1E, red arrow and Fig. $1 \mathrm{~J})$. Taken together, these data show that the cytoplasmic face of poliovirus replication membranes are docking sites for empty and RNA-loaded capsids at both early and late stages of virus replication. 
bioRxiv preprint doi: https://doi.org/10.1101/2021.10.06.463375; this version posted October $6,2021$. The copyright holder for this preprint (which was not certified by peer review) is the author/funder, who has granted bioRxiv a license to display the preprint in perpetuity. It is made available under aCC-BY 4.0 International license.

\section{Enterovirus capsid assembly takes place on membranes and requires VPS34 activity}

Since the RNA loading state and membrane association of complete virions was well resolved in the tomograms (Fig 1A-B), we reasoned that they may also reveal earlier steps in the capsid assembly pathway. Indeed, the tomograms of infected cells at $6 \mathrm{~h}$ p.i. frequently contained novel structures that were consistent with partially assembled capsids (Fig. 2A-C). 96\% of these bona fide capsid intermediates were membrane-associated (58\% SM, 38\% ALM) (Fig. 2D). They contained luminal densities and appeared to be at variable angles to the membranes (Fig. 2B-C), which we concluded was likely to prevent a detailed analysis by subtomogram averaging. We instead characterized them by a simple angle of closure (Fig. 2E, inset), which resulted in an average value of $169^{\circ}$, i.e. closely corresponding to half a capsid (Fig. $2 \mathrm{E}$ ).

Since both capsid intermediates and complete virions were frequently found on ALMs, we sought to investigate the role of the autophagy pathway in virus assembly. We inhibited autophagy using two selective inhibitors: MRT68921 and Vps34-IN1. MRT68921 inhibits the ULK1/ULK2 protein kinases that initiate canonical autophagy (Petherick et al., 2015), whereas Vps34-IN1 inhibits the lipid kinase VPS34 that converts phosphatidylinositol to phosphatidylinositol-3-phosphate (PI(3)P) on the growing phagophore membrane (Bago et al., 2014). Consistent with previous studies, poliovirus infection led to an increased LC3 lipidation at $6 \mathrm{~h}$ p.i. that was not affected by ULK1/ULK2 inhibition (Fig. S3A) (Corona Velazquez et al., 2018). However, co-treating infected cells with the two inhibitors strongly decreased LC3 lipidation (Fig. S3A), and tomograms of such cells revealed a significantly reduced proliferation of both SM and ALM at $6 \mathrm{~h}$ p.i. (Fig. 2F). Strikingly, the concentration of intracellular empty capsids and RNA-loaded virions in these tomograms was lower by one and two orders of magnitude, respectively, compared to the tomograms of untreated cells (Figure 2G,J). This was corroborated by immunostaining for intracellular assembled virions and titration of intracellular infectious virus, which also showed that Vps34-IN1 alone had the same effect as the inhibitor combination (Fig. S3B-D). The decrease in intracellular virions was mirrored by a stark decrease in released infectious virions (Fig. $2 \mathrm{H}$ ). The intracellular viral RNA in drugtreated cells was still $50 \%$ of that in untreated cells (Fig. 2l), suggesting that decreased viral genome replication cannot account for the full two-order-of-magnitude decrease in virus assembly upon drug treatment.

Remarkably, ample capsid assembly intermediates were still present in areas of drug-treated cells that had active membrane proliferation (Fig. 2J-M). The drug treatment did not result in a significant change to the concentration of capsid intermediates on membranes (Fig. 2G), but did lead to a larger proportion of them being on ALMs (Fig S3E), consistent with the 2-fold larger decrease in SM than ALM (Fig. 2F). The distribution of capsid closure values in drugtreated cells was also not significantly different to the untreated cells, with an average of $186^{\circ}$ (Fig. S3F). The stalled progress from capsid intermediates to full capsids in drug-treated cells meant that we could observe a rare, more advanced assembly stage anchored to an ALM (Fig. 2L-M). This snapshot appears to show the transition between the abundant half-capsid intermediates described above, and the complete, membrane-tethered virions (Fig. 1A-B). The densities connecting this near-complete capsid to the membrane appear as separate stalks, unlike the single stalk tethering completed virions. Taken together, the activity of the lipid kinase VPS34 permits increased proliferation of both SM and ALM, and is necessary for the efficient progression of enterovirus assembly beyond the half-capsid intermediate.

Since VPS34 inhibition led to decreased LC3 lipidation (Fig. S3A), we wished to know if the direct assembly host factor was in fact lipidated LC3. To examine the importance of the ATG8 protein subfamilies in virus replication, we infected CRISPR-generated triple knock out (3KO) cells of the LC3 subfamily and 3KO cells for the GABARAP subfamily with PV and imaged them at $6 \mathrm{~h} \mathrm{p.i.} \mathrm{Interestingly,} \mathrm{there} \mathrm{was} \mathrm{a} \mathrm{heterogeneity} \mathrm{of} \mathrm{the} \mathrm{LC3} 3 \mathrm{KO}$ responses to the infection: some cells contained enlarged single-membranes and were devoid of ALMs (Figure S4A), whereas other cells were still capable of forming ALMs in the absence of LC3 (Fig. S4B). The overall abundance of ALMs was significantly lower in LC3 3KO cells (Fig. S4D), which 
bioRxiv preprint doi: https://doi.org/10.1101/2021.10.06.463375; this version posted October 6,2021 . The copyright holder for this preprint (which was not certified by peer review) is the author/funder, who has granted bioRxiv a license to display the preprint in perpetuity. It is made available under aCC-BY 4.0 International license.

was paralleled by a 2- and 3-fold decrease of intracellular empty and RNA-loaded virions, respectively (Fig. S4E). On the other hand, most of the GABARAP $3 K O$ cells accumulated ALMs upon PV infection (Fig. S4C), and there was less change in membrane types and intracellular virus concentration compared to LC3 3KO cells (Fig. S4D-E). Of note, the addition of Vps34-IN1, alone or with MRT68921, had a strong effect in further reducing virus release from both $3 \mathrm{KO}$ cells (Fig. S4F), similar to the effect on wildtype cells (Fig. 2H).

In summary, these data reveal that enterovirus capsid assembly takes place on replication membranes, with a prominent half-capsid intermediate. Activity of the lipid kinase VPS34 enhances viral membrane rearrangements and is required for assembly to progress beyond the half-capsid intermediate. Virus assembly is more dependent on LC3s than on the homologous GABARAPs, but capsid assembly can take place in lieu of either of these proteins more effectively than it can when VPS34 is inhibited.

\section{Virion RNA loading correlates with tethering to replication membranes}

The visualization of capsid intermediates and tethered virions on replication membranes support the notion that RNA loading of capsids takes place on these membranes. To assess this more directly we used Hydantoin (5-(3,4-dichlorophenyl) methylhydantoin), an antiviral drug described to inhibit RNA loading of PV capsids (Vance et al., 1997). Cells were infected with PV and treated with Hydantoin at final concentration of $50 \mu \mathrm{g} / \mathrm{ml}$, which was reported to not interfere with viral RNA replication (Vance et al., 1997). At 6 h p.i., cryo-ET revealed an abundance of empty capsids in the cytoplasm of the treated cells (Fig. 3A-B). The percentage of empty capsids per tomogram was significantly higher in Hydantoin-treated cells than in untreated cells (Fig. 3C). Importantly, the concentration of SMs and ALMs remained unchanged, indicating that Hydantoin, unlike Vps34-IN1, did not affect viral membrane rearrangements (Fig. 3D). Strikingly, initial tomograms also indicated that these empty capsids were no longer tethered to membranes (Fig. 3A-B). To assess this statistically we acquired a set of tomograms on Hydantoin-treated cells and calculated the percentage of tethered particles in treated cells. This revealed that the fraction of particles tethered to membranes was significantly decreased, from $26 \%$ in non-treated cells to $8 \%$ in Hydantoin-treated cells (Fig. 3E). These data provide direct evidence for a link between membrane tethering and the formation of RNA-loaded virions.

\section{Inhibition of ULK1/ULK2 enhances virus production, leading to formation of intracellular virus arrays and increased release}

Inhibition of ULK1 and its homologue ULK2, the initiators of canonical autophagy, did not diminish LC3 lipidation upon viral infection (Fig. S3A). We reasoned that it may nevertheless have other effects on virus replication that may be revealed by cryo-electron tomography. Thus, we recorded cryo-electron tomograms of PV-infected cells treated only with $1 \mu \mathrm{M}$ of the ULK inhibitor MRT68921, without inhibiting VPS34. The tomograms showed similar membrane rearrangements as seen in untreated cells (Fig. 4A-E), and no change in the concentration of SM and ALM (Fig. 4F). Tethering of virions to membranes was still seen (Fig. 4A, yellow arrowheads) and virions were abundant both on the cytoplasmic face of membranes and inside ALMs (Fig. 4A-E). When evaluating several tomograms, we observed a significantly increased concentration of both empty capsids (on average 3-fold, $\mathrm{p}<0.001$ ) and RNA-loaded virions (on average 5-fold, $p<0.01$ ) (Figure $4 G$ ). Consistent with these data, immunofluorescence staining of intracellular mature virions (Fig. S3B-S3C) as well as intracellular genome copies (Fig. S5A) were both increased, albeit not significantly, after MRT68921 treatment. Strikingly, some tomograms of ULK-inhibited cells contained large cytoplasmic virus arrays (Fig. 4H-I). These arrays were not observed in tomograms of untreated cells. They contained virtually only RNAloaded virions and even within the limited thickness of the FIB lamella one array had more than 600 virus particles, geometrically stacked in what seemed to be a close-packing crystal-like arrangement (Fig. $4 \mathrm{H}-\mathrm{I})$. The arrays were surrounded by replication membranes but without any direct link to them (Fig. $4 \mathrm{H}-\mathrm{I}$ ). Since the virus arrays may be present in low numbers per cell, and thus likely to be absent from a single tomogram, we wished to confirm their increased 
bioRxiv preprint doi: https://doi.org/10.1101/2021.10.06.463375; this version posted October $6,2021$. The copyright holder for this preprint

abundance in ULK-inhibited cells by a higher-throughput method. The arrays were large and robust enough to still be identified in high-pressure frozen and freeze-substituted thin sections (Fig. S5B-C) with a general appearance similar to arrays in cryo lamella (Fig. S5D-E). In randomly chosen freeze-substituted sections of cells (Fig. S5B-C, E), arrays were found in 3\% of untreated cells but $56 \%$ of ULK-inhibited cells (Fig. $4 \mathrm{~J}$ ), a significantly higher fraction, thus proving that ULK1/ULK2 inhibition upregulates intracellular virus array formation.

The formation of virus arrays may either be due to a defect in virion release from ULK-inhibited cells, or the arrays may be part of an increased intracellular virion pool en route to release. To discriminate between these two scenarios, we measured released infectious virus from MRT68921-treated cells at different time points and compared it to untreated cells. While extracellular PV titers were unchanged at $6 \mathrm{~h}$ p.i., we measured one order of magnitude increase over untreated cells at $8 \mathrm{~h}$ p.i. (Figure 4K). To determine if the increased release still took place through secretory autophagy we isolated the vesicular fraction. A strong increase in capsid protein as well as LC3 in the vesicular fraction from ULK-inhibited cells confirmed that the virions were released in vesicles positive for LC3 (Fig. 4L). Thus, we conclude that the inhibition of canonical autophagy (ULK1/ULK2) benefits virus replication, leading to the formation of extended intracellular virus arrays that are eventually released in vesicles.

\section{Selective packaging of RNA-loaded virion and contents segregation in autophagy-like membranes}

The observation that virions are tethered when on the outside of ALMs, but not tethered on the inside, (Fig. 1J) gave a first indication that the cryo-electron tomograms can provide structural insights into the process of autophagy of virions. Indeed, when analyzing the tomograms of PV-infected cells at $6 \mathrm{~h}$ p.i. we found examples of several stages of autophagic engulfment of virions ranging from wide open phagophores, to those with a narrow membrane opening and completely sealed DMVs (Fig. 5A-E). We then re-evaluated the statistics of empty capsids and RNA-loaded virions at $6 \mathrm{~h}$ p.i. (Fig. 1F) considering the particle location (outside or inside ALMs). Strikingly, this revealed that autophagic engulfment is a process that strongly selects for RNA-loaded virions. Outside ALMs, empty capsids represent $23 \%$ of particles, whereas only $1 \%$ of particles found inside ALMs were empty capsids (Fig. 5F).

We further categorized ALMs based on the appearance of their contents in the tomograms. Classes of ALMs with different contents were clearly discernible (Fig. 5H-M). The most abundant class was ALMs containing RNA-loaded virions, at 52\% (Fig. 5G). The second most abundant class, at $15 \%$, was ALMs containing amorphous granular material that was clearly denser than the remaining cytoplasmic contents (Fig. 5G,H). These dense granules were frequently co-packed with virions (Figure $5 \mathrm{G}, \mathrm{J}$ ). One distinct class representing $13 \%$ of ALMs contained bundles of protein filaments of homogeneous width (Fig. 5I, S6A-D). Interestingly, this class was different in the sense that the filament bundles, as opposed to dense granules, were rarely co-packaged with virions (Fig. 5G,L) or with dense granules (Fig. 5G and 5M). The filaments had a different dependence on the autophagy pathway than virion formation since they were not affected by VPS34 inhibition, but instead completely absent in the LC3 and GABARAP 3KO cells (Fig. S6A), i.e. the opposite pattern compared to virus replication. The filaments were exclusively found in ALMs, in bundles, and with a visible helical twist (Fig. S6BC). We determined the filaments' structure by subtomogram averaging to $18.5 \AA$ resolution ( $F S C=0.143$ gold-standard criterion, Fig. S6E), which yielded a helix with an average diameter of $10 \mathrm{~nm}, 29^{\circ}$ twist and $52 \AA$ rise per subunit (Fig. S6E and S7). From the $18.5 \AA$ map the identity of the filament could not be positively determined. However, the map was detailed enough to allow definitive exclusion of candidate filaments. We systematically compared the filament to all classes of mammalian protein filaments deposited in the electron microscopy database (no filaments consisting of picornaviral proteins had been deposited). After doing so, based on shape and size we could exclude all deposited filaments except decorated actin filaments (Fig. S7 and Table S3 for complete list). Thus, the filament is either actin decorated 
bioRxiv preprint doi: https://doi.org/10.1101/2021.10.06.463375; this version posted October $6,2021$. The copyright holder for this preprint

(which was not certified by peer review) is the author/funder, who has granted bioRxiv a license to display the preprint in perpetuity. It is made available under aCC-BY 4.0 International license.

by a vinculin-like actin-binding protein, or an unknown viral or cellular protein filament of similar size and shape.

Altogether, these data reveal an exquisite specificity in virus-induced autophagy: autophagic membranes selectively engulf RNA-loaded virions while excluding empty capsids, and copackage virions with dense granular material while segregating them from a second class of ALMs that contains bundles of protein filaments.

\section{Discussion}

Here we present an in situ structural analysis of enterovirus replication by cryo-electron tomography. Our study focuses on the involvement of autophagic membranes in virion assembly and egress, and are consistent with the model presented in Fig. 6. All positive-sense RNA viruses utilize cytoplasmic membranes to form their RNA replication organelles, often referred to as replication complexes (RCs) (Miller and Krijnse-Locker, 2008; Romero-Brey and Bartenschlager, 2014). It has been proposed to subdivide RCs into two broad categories based on their membrane topology: tightly curved membrane buds that replicate the RNA within the lumen of the bud (e.g. alphaviruses and flaviviruses), and larger double-membrane vesicles (Paul and Bartenschlager, 2013). Enteroviruses belong to the second category, as do e.g. coronaviruses (Wolff et al., 2020b). There is little to no sequence similarity between the membrane-remodeling proteins of enteroviruses and coronaviruses, but it has not been known to what extent this would be reflected in the structural organization of their RCs. Recent cryoET data on coronavirus RCs have revealed them to be DMVs containing dsRNA, and presumably the replication machinery, in their lumen and having a narrow, defined proteinaceous pore to the cytoplasm (Klein et al., 2020; Wolff et al., 2020a). Our data reveal fundamental differences between enterovirus and coronavirus RCs. Open, phagophore-like structures are abundant in enterovirus-infected cells in addition to DMVs (Fig. 1). Also, while our tomograms cannot directly visualize the RNA replication, the location of capsid assembly (Fig. 2) suggests that the cytoplasmic face of autophagy-like membranes (ALMs) and singlemembraned tubes and vesicles (SMs) are also the site of enterovirus genome replication, whereas the interior of ALMs consists of autophagized material such as virions en route to be released through secretory autophagy (Mutsafi and Altan-Bonnet, 2018).

Compared to viral RNA replication, less has been known about the site and pathway of enterovirus assembly. The identification of a direct interaction between the membrane-bound helicase $2 \mathrm{C}$ and the capsid protein VP3 suggested a membrane-proximal location of the assembly (Jiang et al., 2014), but direct evidence has been missing. In tomograms of infected cells, we identified a novel and abundant structure not reported in cryo-electron tomograms of uninfected cells (Fig. 2, Fig. S2A-B). This bona fide capsid assembly intermediate is structurally equivalent to half of an enterovirus capsid, and is to $96 \%$ found directly docked to membranes in infected cells. It was found at roughly equal proportions on the cytosolic face of SMs and ALMs, suggesting that these two membrane types are equivalent as virus assembly platforms. In fact, a prominent capsid-related species with a sedimentation coefficient of 45-53S, i.e. approximately half of an empty capsid (75-80S), was reported in early fractionation studies of enterovirus-infected cells but was not assigned a precise identity (Rombaut et al., 1985; Su and Taylor, 1976). Additionally, subcellular membrane fractions from poliovirus-infected cells have been shown to be positive for capsid antigens in immuno-EM, in which they displayed surface structures consistent with the half-capsid intermediate present in our tomograms (Pfister et al., 1992). The abundance of this specific, large capsid intermediate must correlate with it being a local free energy minimum along the assembly pathway. The current paradigm of non-enveloped virus assembly holds that the proteinaceous capsid either assembles independently of other components (followed by energy-expending genome loading), or is templated through interactions between capsid subunits and the genome (Twarock et al., 2018). Our finding of a half-capsid intermediate consistently docked to membranes extends that paradigm and suggests that enterovirus assembly is directly guided by the replication 
bioRxiv preprint doi: https://doi.org/10.1101/2021.10.06.463375; this version posted October 6,2021 . The copyright holder for this preprint (which was not certified by peer review) is the author/funder, who has granted bioRxiv a license to display the preprint in perpetuity. It is made available under aCC-BY 4.0 International license.

membrane and its bound components. A relatively slow transition beyond the half-capsid intermediate may help ensure that incorporation of the genomic RNA has progressed sufficiently before the capsid closes further. We also identify the host-cell lipid kinase VPS34, which is responsible for production of $\mathrm{PI}(3) \mathrm{P}$ of the growing phagophore membrane, as a necessary host factor for progression beyond the half-capsid intermediate. Pharmacological inhibition of VPS34 resulted in reduction of membrane proliferation, intracellular viral RNA levels, as well as strikingly reduced intracellular virion concentration whereas the half-capsid intermediate was still present at similar levels (Fig. 2). This is consistent with the half-capsid intermediate being a checkpoint for RNA incorporation. Earlier work had suggested a "late proofreading" mechanism that would ensure that only recently produced viral RNA, present in the vicinity of the RC, is incorporated into virions (Nugent et al., 1999). Our data are consistent with this model and identify the half-capsid intermediate as the likely key structural species in this process. Notably, the effect of VPS34 inhibition was stronger than a triple LC3 knock out, even though we did observe a decrease in membrane proliferation and intracellular virus concentration in the LC3 $3 \mathrm{KO}$ cells (Fig. S4). On the other hand, no changes in membrane proliferation nor intracellular virus concentration was seen in GABARAP 3 KO cells. The LC3 and GABARAP proteins all become conjugated to phosphatidylethanolamine upon autophagy induction and play subtly different roles in autophagy. Our data show that they are also of different importance to enterovirus replication, with LC3s being more important than GABARAPs.

The cryo-electron tomograms revealed several layers of selectivity in enterovirus-induced autophagy (Fig. 5). Perhaps most remarkably, there is a strong selectivity for packaging of RNA-loaded virions over empty capsids. In normal cellular physiology autophagy is often a selective process, with selectivity being mediated by a multitude of autophagy receptors. These proteins recognize specific motifs on cytoplasmic components and link them to the growing phagophore membrane via interaction with lipidated LC3 (Gatica et al., 2018). The case of enterovirus particles thus seems to present a conundrum: How can phagophores selectively package RNA-loaded virions over empty capsids when the external surfaces of both these particles are virtually identical (Basavappa et al., 1994)? While our data don't provide a definitive answer, they suggest a mechanism involving the link between membrane tethering and RNA loading. By using the encapsidation-inhibiting drug Hydantoin we identified that RNA loading of capsids correlates with their membrane tethering (Fig. 3). Furthermore, virions are tethered when on the outside of ALMs, but no longer when they are in the lumen of ALMs (Fig. $1 \mathrm{~J})$. This suggests a model by which virus assembly starts on a membrane, progresses though the half-capsid intermediate to RNA-loaded virions that remain membrane-tethered until they are handed over to a phagophore, inside of which they lose the tethering. The selectivity would thus be a consequence of the timing of the untethering of RNA-loaded virions. This normal scenario was slightly altered in cells inhibited for ULK1 (and its homologue ULK2), where the autophagic engulfment seemed unable to keep up with the virus production, resulting in formation of vast arrays of untethered virions in the cytoplasm and a subsequent increase in virus release at later time points (Fig. 4). Canonical autophagy is initiated by the protein kinase ULK1, but enterovirus-induced autophagy is ULK1-independent, and ULK1 has in fact been reported to be partially depleted in infected cells (Corona Velazquez et al., 2018). Based on our data we propose that autophagy in enterovirus replication is a balance between a virusinduced, proviral form of autophagy, and the canonical ULK1-dependent autophagy that still serves to restrict virus replication. This would explain the benefit to the virus in degrading ULK1. Other examples of viral tuning of autophagy have been described, such as the degradation of SNAP29, the SNARE that would otherwise mediate fusion of virus-loaded autophagosomes with lysosomes (Corona et al., 2018; Mohamud et al., 2018).

Another aspect of autophagic selection was revealed by studying the non-viral contents of ALMs in infected cells (Fig. 5). Viruses were frequently copackaged with dense granular material which has also been described in cryo-electron tomograms of vesicles released from infected cells (Yang et al., 2020). These granules are irregular in size and shape but their high electron density is compatible with them containing RNA, which could mean that non- 
bioRxiv preprint doi: https://doi.org/10.1101/2021.10.06.463375; this version posted October 6,2021 . The copyright holder for this preprint (which was not certified by peer review) is the author/funder, who has granted bioRxiv a license to display the preprint in perpetuity. It is made available under aCC-BY 4.0 International license.

encapsidated viral RNA is released in the same vesicles as virions. On the other hand, virions were markedly segregated from a different type of abundant ALM contents: bundles of protein filaments. Whereas the subtomogram average of these filaments could not positively determine their identity, it was sufficient to definitively rule out practically all candidate filaments with a known structure, such as F-actin and immunity-related filaments like MDA5-dsRNA (Fig. S7). At the resolution obtained, the subtomogram average was only consistent with available structures of $\mathrm{F}$-actin decorated with e.g. the vinculin actin-binding domain. This tentative identification of the autophagy-associated filaments with decorated actin ties together two previous reports related to F-actin in enterovirus infection, and autophagy, respectively. Firstly, it has been reported that the actin cytoskeleton largely disappears in enterovirus-infected cells (Sobo et al., 2012). Secondly, the actin cytoskeleton has been shown to disappear in starved cells (i.e. during autophagy activation), followed by reappearance of F-actin fluorescence in the lumen of LC3-positive autophagic membranes, which was interpreted as actin playing a role in shaping autophagic membranes (Mi et al., 2015). In light of this, we suggest that the filament-filled ALMs in our tomograms may represent snapshots of autophagic actin degradation in infected cells. Interestingly, the appearance of the filament bundles had a different host-factor dependence than that of virion formation, and autophagic membrane shapes were formed effectively in GABARAP KO cells which had no filament bundles (Fig. S6). This indicates that the filament bundles, at least in the case of enterovirus-induced autophagy, are not a necessary step towards forming autophagosomes.

In summary, our study of poliovirus-infected cells by cryo-electron tomography reveals membrane-templated capsid assembly and a link between membrane tethering and RNAloading of virions. It further shows how intricate and multi-faceted autophagy-related processes take place in enterovirus-infected cells, balancing virion production and membrane engulfment, making sure that only RNA-loaded virions are packaged in phagophores and segregating them from certain other types of autophagic cargoes.

\section{Acknowledgments}

We would like to thank Carlson lab members, Sven Carlsson, and Richard Lundmark for constructive suggestions, Dale Corkery for help with the LC3 lipidation assay, as well as Nitesh Mistry for help with virus purification (all Umeå University). We are also thankful to Sebastian Schultz and Andreas Brech (Oslo University) for sharing their experience in freeze substitution.

Cryo-EM data were collected at the Umeå Centre for Electron Microscopy (UCEM), a SciLifeLab National Cryo-EM facility and part of National Microscopy Infrastructure, NMI VRRFI 2016-00968), supported by instrumentation grants from the Knut and Alice Wallenberg Foundation and the Kempe Foundations.

This project was funded by a postdoctoral grant to S.D. from the European Union's Horizon 2020 research and innovation programme under the Marie Skłodowska-Curie grant agreement No 795892. Additional funding came from the Human Frontier Science Program (Career Development Award CDA00047/2017-C to L.-A.C.), the Knut and Alice Wallenberg Foundation (through the Wallenberg Centre for Molecular Medicine Umeå). N.A.-B. and AK were intramurally funded by the National Institutes of Health (USA).

\section{Author Contributions}

S.D., A.K., K.S., N.A.-B., L.-A.C. conceived the project. S.D. performed cryo-electron tomography. A.K. performed virus replication and egress assays. S.D., D.R.M., L.-A.C. performed subtomogram averaging. S.D., A.K., K.S., B.A., D.R.M., N.A.-B., L.-A.C. analyzed data. S.D., L.-A.C. wrote the original draft. All authors reviewed and edited the manuscript. 


\section{Declaration of Interests}

The authors declare no competing interests.

\section{Methods}

KEY RESOURCES TABLE

\begin{tabular}{|c|c|c|}
\hline REAGENT or RESOURCE & SOURCE & IDENTIFIER \\
\hline \multicolumn{3}{|l|}{ Antibodies } \\
\hline Rabbit monoclonal anti-LC3B (D11) & Cell signaling & 3868 \\
\hline Rabbit monoclonal anti-LC3B & Abclonal & A19665 \\
\hline Mouse monoclonal Anti- $\beta$-Actin & Sigma & A2228 \\
\hline Mouse monoclonal anti-VP1 & $\begin{array}{l}\text { Homemade, clone } \\
\mathrm{B} 3 / \mathrm{H} 1\end{array}$ & $\mathrm{~N} / \mathrm{A}$ \\
\hline Rabbit polyclonal anti-3D & $\begin{array}{l}\text { Gifted by George } \\
\text { Belov (UMD) }\end{array}$ & $\mathrm{N} / \mathrm{A}$ \\
\hline Human anti-A12 & $\begin{array}{l}\text { Gifted by Konstantin } \\
\text { Chumakov (FDA) }\end{array}$ & $\mathrm{N} / \mathrm{A}$ \\
\hline $\begin{array}{l}\text { Goat anti-Rabbit lgG }(\mathrm{H}+\mathrm{L}) \text { Cross-Adsorbed } \\
\text { Secondary Antibody, Alexa Fluor } 555\end{array}$ & Invitrogen & A21428 \\
\hline $\begin{array}{l}\text { Goat anti-Human IgG }(\mathrm{H}+\mathrm{L}) \text { Cross-Adsorbed } \\
\text { Secondary Antibody, Alexa Fluor } 488\end{array}$ & Invitrogen & A11013 \\
\hline \multicolumn{3}{|l|}{ Bacterial and virus strains } \\
\hline Poliovirus Type 1 Mahoney strain & $\begin{array}{l}\text { Gifted by George } \\
\text { Belov (UMD) }\end{array}$ & $\mathrm{N} / \mathrm{A}$ \\
\hline \multicolumn{3}{|l|}{ Chemicals, peptides, and recombinant proteins } \\
\hline MRT68921 & Merck & SML1644 \\
\hline VPS34IN1 & Cayman chemicals & 17392 \\
\hline $\begin{array}{l}\text { Hydantoin - } \quad \text { 5-(3,4-dichlorophenyl)-5- } \\
\text { methylimidazolidine-2,4-dione }\end{array}$ & Cayman chemicals & EN300-21815 \\
\hline \multicolumn{3}{|l|}{ Reagents } \\
\hline Pierce $^{\mathrm{TM}}$ BCA Protein Assay Kit & $\begin{array}{l}\text { ThermoFisher } \\
\text { Scientific }\end{array}$ & 23225 \\
\hline $\begin{array}{l}\text { SuperSignal }{ }^{\mathrm{TM}} \text { West Femto Maximum Sensitivity } \\
\text { Substrate }\end{array}$ & $\begin{array}{l}\text { ThermoFisher } \\
\text { Scientific }\end{array}$ & 34094 \\
\hline SuperSignal ${ }^{\mathrm{TM}}$ West Pico PLUS Substrate & Thermo Scientific & 34580 \\
\hline DMEM high glucose & Gibco & 11965118 \\
\hline \multicolumn{3}{|l|}{ MEM } \\
\hline Pen/Strep & Corning & $30-002-\mathrm{Cl}$ \\
\hline FBS & Atlas Biological & EF-05-00A \\
\hline PFA & EMS & 15710 \\
\hline DPBS & Gibco & 14190144 \\
\hline Trypsin-EDTA & Lonza & 17-161E \\
\hline Dapi Fluoromount-G & EMS & 17984-24 \\
\hline Saponin & Sigma-Aldrich & S4521 \\
\hline Laemmli Sample Buffer & Bio-Rad & 1610747 \\
\hline Trans-Blot Turbo 5X buffer & Bio-Rad & 10026938 \\
\hline TBS & Bio-Rad & 1706435 \\
\hline Tween-20 & Affymetrix & $90005-04-5$ \\
\hline Blotting Grade Blocker Dry Milk & Bio-Rad & 1706404 \\
\hline Quick-RNA Microprep Kit & Zymo Research & R1051 \\
\hline
\end{tabular}




\begin{tabular}{|c|c|c|}
\hline Maxima FirstStrand cDNA Synthesis & Fisher Scientific & FERK1642 \\
\hline SYBR Green Supermix & Bio-Rad & 1725124 \\
\hline Formaldehyde & Macron Chemicals & $5016-02$ \\
\hline Ethyl Alcohol & Sigma-Aldrich & E7023 \\
\hline Methanol & Fisher Chemical & A452-4 \\
\hline Cristal Violet & Sigma-Aldrich & C3886 \\
\hline \multicolumn{3}{|l|}{ Deposited data } \\
\hline subtomogram average of protein filament & This study & $\mathrm{XXX}$ \\
\hline \multicolumn{3}{|l|}{ Experimental models: Cell lines } \\
\hline HeLa & ATCC & CRM-CCL-2 ${ }^{\mathrm{TM}}$ \\
\hline HeLa 3KO LC3 & (Nguyen et al., 2016) & $\mathrm{N} / \mathrm{A}$ \\
\hline HeLa 3KO GABARAP & (Nguyen et al., 2016) & $\mathrm{N} / \mathrm{A}$ \\
\hline \multicolumn{3}{|l|}{ Primer sequences } \\
\hline $\begin{array}{l}\text { Poliovirus Forward primer } \\
5 \text { 'CGGCTAATCCCAACCTCG 3' }\end{array}$ & IDT & $\mathrm{N} / \mathrm{A}$ \\
\hline $\begin{array}{l}\text { Poliovirus Reverse primer } \\
\text { 5' CACCATAAGCAGCCACAATAAAATAA 3' }\end{array}$ & IDT & $\mathrm{N} / \mathrm{A}$ \\
\hline $\begin{array}{l}\text { GAPDH Forward primer } \\
5 \text { ‘ AACATCATCCCTGCСТCTACTGG } 3\end{array}$ & IDT & $\mathrm{N} / \mathrm{A}$ \\
\hline $\begin{array}{l}\text { GAPDH Reverse primer } \\
\text { 5' GTTTTTCTAGACGGCAGGTCAGG 3' }\end{array}$ & IDT & $\mathrm{N} / \mathrm{A}$ \\
\hline \multicolumn{3}{|l|}{ Software and algorithms } \\
\hline SerialEM & (Mastronarde, 2005) & $\begin{array}{l}\text { RRID:SCR_01729 } \\
3\end{array}$ \\
\hline MotionCor2 & (Zheng et al., 2017) & $\begin{array}{l}\text { RRID:SCR_01649 } \\
9\end{array}$ \\
\hline CTFFIND4 & $\begin{array}{l}\text { (Rohou and } \\
\text { Grigorieff, 2015) }\end{array}$ & $\begin{array}{l}\text { RRID:SCR_01673 } \\
2\end{array}$ \\
\hline IMOD & (Kremer et al., 1996) & $\begin{array}{l}\text { RRID:SCR_00329 } \\
7\end{array}$ \\
\hline Amira & & $\begin{array}{l}\text { RRID:SCR_00735 } \\
3\end{array}$ \\
\hline filament tracing module in Amira & (Rigort et al., 2012) & \\
\hline UCSF Chimera & $\begin{array}{l}\text { (Pettersen et al., } \\
\text { 2004) }\end{array}$ & $\begin{array}{l}\text { RRID:SCR_00409 } \\
7\end{array}$ \\
\hline Dynamo & $\begin{array}{l}\text { (Castano-Diez et al., } \\
\text { 2012; Castano-Diez } \\
\text { et al., 2017) }\end{array}$ & \\
\hline PyTom & (Hrabe et al., 2012) & \\
\hline subTOM & $\begin{array}{l}\text { https://www2.mrc- } \\
\text { Imb.cam.ac.uk/grou } \\
\text { ps/briggs/resources }\end{array}$ & \\
\hline Matlab & & $\begin{array}{l}\text { RRID:SCR_00162 } \\
2\end{array}$ \\
\hline ImageJ & $\begin{array}{l}\text { https://imagej.nih.go } \\
\text { v/ij/ }\end{array}$ & $\begin{array}{l}\text { RRID:SCR_00307 } \\
0\end{array}$ \\
\hline GraphPad Prism & & $\begin{array}{l}\text { RRID:SCR_00279 } \\
8\end{array}$ \\
\hline
\end{tabular}


bioRxiv preprint doi: https://doi. org/10.1101/2021.10.06.463375; this version posted October 6, 2021. The copyright holder for this preprint

\section{RESOURCE AVAILABILITY}

\section{Lead contact}

Further information and requests for resources and reagents should be directed to and will be fulfilled by the lead contact, Lars-Anders Carlson (lars-anders.carlson@umu.se).

\section{Data and code availability \\ Cryo-EM map of the filament structure has been deposited in the Electron Microscopy Data Bank (EMDB) under accession code EMD-xxxxx. Any additional information required to reanalyze the data reported in this paper is available from the lead contact upon request.}

\section{METHOD DETAILS \\ Cell lines and cultures}

HeLa cells were obtained from ATCC (\# CRM-CCL-2 ${ }^{\text {TM }}$ ). HeLa LC3 and GABARAP 3KO cells were described previously (Nguyen et al., 2016). All cell lines were grown in (D)MEM supplemented with $10 \%$ fetal bovine serum (FBS)/25mM HEPES/GlutaMAX ${ }^{\mathrm{TM}} /$ Penicillin/Streptomycin and maintained at $37^{\circ} \mathrm{C}$ in a $5 \% \mathrm{CO}_{2}$ atmosphere. Cells were regularly screened for the presence of mycoplasma infection.

\section{Drug treatments}

HeLa cells were pre-treated with DMSO or $1 \mu \mathrm{M}$ MRT68921 in culture medium, $1 \mathrm{~h}$ before the infection. Medium was replaced with serum free media containing DMSO or $1 \mu$ M MRT68921 and cells were infected with Poliovirus (PV) at MOI 5 for $1 \mathrm{~h}$. Inoculum was then removed, and cells were incubated in fresh media containing $2 \%$ FBS and $1 \mu \mathrm{M}$ MRT68921 and/or $5 \mu \mathrm{M}$ Vps34-IN1 or $50 \mu \mathrm{g} / \mathrm{mL}$ hydantoin for $3 \mathrm{~h}$ to $8 \mathrm{~h}$. Vps34-IN1 was added to the cell media at $1 \mathrm{~h}$ p.i. to not interfere with the endocytosis-based viral entry. Hydantoin was added at $1 \mathrm{~h} \mathrm{p.i.} \mathrm{After}$ addition, all inhibitors were kept in the cell media throughout the experiments.

\section{LC3 lipidation assay}

For each condition and time point, HeLa cells were seeded in two T25 flasks ( $2 \times 10^{6}$ cells/flask) and infected with poliovirus at $\mathrm{MOI} 5$. Infected cells were collected by trypsinization, then centrifuged at $500 \mathrm{~g}$ for $5 \mathrm{~min}$, pellets were resuspended in PBS and washed twice with PBS. Cells were lysed with lysis buffer $(20 \mathrm{mM}$ Tris- $\mathrm{HCl}$ pH8, $300 \mathrm{mM} \mathrm{KCl}, 10 \%$ glycerol, $0.25 \%$ Nonidet P-40, $0.5 \mathrm{mM}$ EDTA, $0.5 \mathrm{mM}$ EGTA) on ice for $15 \mathrm{~min}$, passed through a $22 \mathrm{G}$ needle and centrifuged at $15,000 \mathrm{rpm}$ for $20 \mathrm{~min}$. After centrifugation, supernatants were stored at $80^{\circ} \mathrm{C}$ and protein concentrations were further determined using the BCA protein assay reagent.

\section{SDS-PAGE/Western Blot}

Proteins were separated by SDS-PAGE and gels were transferred via a semi-dry blotter to PVDF transfer membranes and blocked for $1 \mathrm{~h}$ with TBS-T containing $5 \%(\mathrm{w} / \mathrm{v})$ milk powder or $5 \%(\mathrm{w} / \mathrm{v}) \mathrm{BSA}$, followed by probing with primary antibodies and overnight incubation, and further re-probed with corresponding HRP conjugated secondary antibodies (Sigma Aldrich) for $1 \mathrm{~h}$. Blots were developed using SuperSignal West Pico PLUS Chemiluminescent Substrate (Thermo Scientific) and imaged using the Amersham Imager 600 (GE Healthcare Biosciences) or the Biorad ChemiDoc ${ }^{\mathrm{TM}}$ Touch, and analyzed with imageJ. 
bioRxiv preprint doi: https://doi.org/10.1101/2021.10.06.463375; this version posted October 6,2021 . The copyright holder for this preprint (which was not certified by peer review) is the author/funder, who has granted bioRxiv a license to display the preprint in perpetuity. It is made available under aCC-BY 4.0 International license.

\section{Sample preparation for cryo-electron tomography}

24h before infection, cells were seeded on R2/2 gold UltrAufoil grids (200 mesh, Quantifoil Micro Tools $\mathrm{GmbH}$, Großlöbichau, Germany) in $\mu$-Slide 8 Well chamber (IBIDI) at $2 \times 10^{4}$ cells/well. Prior to use, UltrAufoil grids were glow-discharged, dipped in ethanol and then washed with cell media for $30 \mathrm{~min}$. HeLa cells were infected with poliovirus at MOI 5 for $1 \mathrm{~h}$ in serum-free media at $37^{\circ} \mathrm{C}$. The $\mu$-Slide was gently agitated every $15 \mathrm{~min}$ to ensure an even coverage and maximize virus contact with the cell monolayer. After $1 \mathrm{~h}$ of virus absorption, the inoculum was replaced with fresh DMEM media supplemented with $2 \%$ FBS. Infected cells were plunge-frozen in liquid ethane-propane mix $3 \mathrm{~h}$ or $6 \mathrm{~h}$ post-infection using a Vitrobot plunge freezer (Thermo Fisher Scientific) at $23^{\circ} \mathrm{C}, 90 \%$ humidity, with blot force -5 and blot time 6.5 s.

\section{Cryo-lamella generation and characterization}

Cryo-lamellas of poliovirus-infected cells were generated employing the wedge-milling method (Schaffer et al., 2017) using a Scios focused-ion-beam scanning electron microscope (ThermoFisher Scientific). To prevent sample drift during the milling process and to enhance sample conductivity, the samples were first coated with platinum using the gas injection system (GIS, ThermoFisher Scientific) operated at $26^{\circ} \mathrm{C}$, at $12 \mathrm{~mm}$ stage working distance and 7 seconds gas injection time. The milling was performed at a tilt angle within a range of $17^{\circ}-23^{\circ}$ stage tilt. Lamella preparation was performed in a stepwise milling using parallel rectangular pattern above and below the area of interest, with reducing the ion beam current throughout the milling process, from $0.3 \mathrm{nA}$ for the first milling step to remove the bulk material to $0.03 \mathrm{nA}$ at the final cleaning step to obtain the lamella which was set to a minimum thickness of 200 $\mathrm{nm}$. To minimize the contamination of lamellas with ice crystals, they were stored in liquid nitrogen for less than a week before tilt-series collection at the Titan Krios (ThermoFisher Scientific). The final thickness of lamellas was measured at the Titan Krios. Two images of the same area of a lamella were recorded at an intermediate magnification (8700x): an energyfiltered image ( $F$ image), and non-filtered image for which the energy filter slit was removed $\left(\mathrm{nF}\right.$ image). The lamella thickness was estimated as $350^{*} \ln (\mathrm{I}(\mathrm{nF}) / \mathrm{I}(\mathrm{F}))$, where $\mathrm{I}(\mathrm{nF})$ and $\mathrm{I}(\mathrm{F})$ are the intensities in the non-filtered and filtered images, respectively, and 350 the estimate of the electron mean-free path at $300 \mathrm{kV}$ in ice (in $\mathrm{nm}$ ).

\section{Cryo-electron tomography}

Data was collected using a Titan Krios (ThermoFisher Scientific) operated at $300 \mathrm{kV}$ in parallel illumination mode. Tilt series were recorded using SerialEM software on a K2 Summit detector (Gatan, Pleasanton, CA) operated in super-resolution mode. The K2 Summit detector was mounted on a BioQuantum energy filter (Gatan, Pleasanton, CA) operated with a $20 \mathrm{eV}$ slit width. A condenser aperture of $70 \mu \mathrm{m}$ and an objective aperture of $100 \mu \mathrm{m}$ were chosen for tilt-series collection. Coma-free alignment was performed with AutoCtf/Sherpa (ThermoFisher Scientific). Tilt-series were acquired in dose-symmetric or bi-directional mode. Due to the pretilt of the lamellas, the starting angle used was $+13^{\circ}$ for dose-symmetric, and $-21^{\circ}$ to $-25^{\circ}$ for bi-directional tilt series acquisition. The following parameters were used for acquisition: $33 \mathrm{kx}$ nominal magnification corresponding to a specimen pixel size of $2.145 \AA$; defocus range -3 to $-5 \mu \mathrm{m}$, tilt-range depending on the lamella pre-tilt and thickness typically $\pm 50^{\circ}$ to $\pm 60^{\circ}$; tilt increment $2^{\circ}$ or $3^{\circ}$; total electron dose $\sim 100 \mathrm{e}-/ \AA^{2}$ (bidirectional tilt series) and $130 \mathrm{e}-/ \AA 22$ (dosesymmetric tilt series). The exposure dose was not varied as a function of tilt angle. At each tilt angle, the exposure was saved as a non-gain-corrected TIFF movie containing a dose per frame of around 0.25 per super-resolution pixel.

\section{Cryo-electron tomography data processing}

Super-resolution TIFF movies were unpacked and gain-reference corrected, and subsequently corrected for sample motion using MotionCor2 (Zheng et al., 2017). The motion correction included a factor 2 binning resulting in a specimen pixel size of $4.29 \AA$. After reassembly of tiltseries image stacks they were processed using IMOD (Kremer et al., 1996). Tilt series were aligned using patch tracking. The aligned stacks were CTF-corrected with a custom-made script using CTFFIND4 (Rohou and Grigorieff, 2015) and CTFPHASEFLIP (Xiong et al., 2009), 
bioRxiv preprint doi: https://doi.org/10.1101/2021.10.06.463375; this version posted October $6,2021$. The copyright holder for this preprint (which was not certified by peer review) is the author/funder, who has granted bioRxiv a license to display the preprint in perpetuity. It is made available under aCC-BY 4.0 International license.

a part of IMOD (Kremer et al., 1996). Tomograms were then generated in IMOD using weighted back projection, no low-pass filtering was performed at this stage. For visualization, tomograms were 4 times binned using IMOD, resulting in a pixel size of $17.16 \AA$ and denoised using the boxfilter option in Amira software (ThermoFisher Scientific). Filtered tomograms were further segmented using Amira for the representation of membranes, protein densities and filaments, the last using the Fiber tracing module. Subtomogram averages of empty capsids and RNAloaded virions were integrated in these $3 \mathrm{D}$ renderings through UCSF Chimera (Pettersen et al., 2004).

\section{Subtomogram averaging of viruses}

Subtomogram averaging of virus particles for visualization purposes was performed using Dynamo (Castano-Diez et al., 2012; Castano-Diez et al., 2017). For RNA-loaded virions, a total of 300 particles were manually picked in two tomograms containing the cytoplasmic virus arrays (MRT68921-treated cells). For empty viruses, a total 198 particles were manually picked in two tomograms from Hydantoin-treated cells. Subvolumes of unbinned particles $(4.29 \AA / p x)$ were extracted with a box size of $100 * 100 * 100$ voxels. Subvolumes were first iteratively aligned against each other allowing only shifts using a spherical mask with radius of 48px and a Gaussian falloff of $3 \mathrm{px}$. After centering particles, a full rotational alignment was performed. The average was realigned to icosahedral symmetry axes and a final average was calculated with imposed icosahedral symmetry. Gold-standard FSC curves for resolution estimation of the virus averages were calculated in Dynamo, resulting in a resolution estimate of $25 \AA$ for empty capsids and $30 \AA$ for RNA-loaded virions at a Fourier shell correlation threshold of 0.143 . Subtomogram averages were low-pass filtered to their respective resolution and the $3 D$ renderings were created in UCSF Chimera.

\section{Subtomogram averaging of filaments}

The subtomogram selection, extraction and averaging followed the workflow schematically presented in Fig. S8. 1856 filaments were traced in 16 tomograms using the fiber tracing module (Rigort et al., 2012) in Amira (Thermo Fisher Scientific). The tracing was performed within manually segmented regions corresponding to filament-filled autophagy-like membranes, and the tracing parameters were selected so that the number and length of the filaments was consistent with their visual appearance in the tomograms. Filament coordinates were exported from Amira and imported to Dynamo using a custom-written MATLAB (Mathworks) script, after which Dynamo was used to extract subtomograms at regular intervals. Initially, an oversampled subtomogram extraction was performed, with (100px)^3 subtomograms extracted along the filament axis at 5 px intervals. This resulted in 55,376 subtomograms. Each subtomogram was assigned initial Euler angles that aligned it with the traced filament axis, but gave it a randomized rotation along that axis. The subsequent alignments and classifications were performed using a cylindrical mask with a radius of $16 \mathrm{px}$ and a Gaussian falloff of 3 or 5 px. Subtomogram averaging was performed in Dynamo. After an initial single iteration allowing for centering of the subtomograms perpendicularly to the filament axis, several iterations were performed allowing for shifts, free rotations around the filament axis and $a+/-30^{\circ}$ tilt with respect to the filament axis. At this stage of the data processing, efforts to determine filament polarity by allowing each subtomogram in a given filament to change orientation during alignment, and then imposing the majority orientation on all subunits of the filament were not yet successful. From the full oversampled dataset, overlapping subtomograms were removed using a distance threshold of 10 px (42.9 $\AA$ ), resulting in a set of 16,682 subtomograms. These subtomograms were subjected to a fiveclass multireference alignment (MRA) in Dynamo. Three of the five classes had a similar, regular helical appearance, and were pooled for a second round of MRA with five classes, from which one class of 3517 subtomograms was better defined than the others. This class was subjected to a half-set gold-standard refinement in Dynamo resulting in a resolution estimate of $23.8 \AA$ at a Fourier shell correlation threshold of 0.143 . The resulting average allowed a first estimation of the helical parameters as a rise of $\sim 56 \AA$ per subunit and a rotation of $\sim 36^{\circ}$ per subunit. At this point, tomograms were re-reconstructed using NovaCTF to allow for 3D CTF correction by phase flipping (Turonova et al., 2017). Subtomograms were reextracted at 
bioRxiv preprint doi: https://doi.org/10.1101/2021.10.06.463375; this version posted October $6,2021$. The copyright holder for this preprint (which was not certified by peer review) is the author/funder, who has granted bioRxiv a license to display the preprint in perpetuity. It is made available under aCC-BY 4.0 International license.

positions corresponding to the helical subunits, which after removal of overlapping particles resulted in an enlarged data set of 10897 subtomograms. These subtomogram poses and positions were exported from Dynamo for further processing in the subTOM package written in MATLAB with functions adapted from the TOM (Nickell et al., 2005), AV3 (Förster et al., 2005) and Dynamo packages. The scripts and relevant documentation are available to download [https://www2.mrc-Imb.cam.ac.uk/groups/briggs/resources]. Additionally, instead of a binary wedge mask, a modified wedge mask was used (Wan et al., 2017). The missing wedge was modelled at all processing stages as the average of the amplitude spectra of subtomograms extracted from regions of each tomogram containing empty ice, and was applied during alignment and averaging. We applied both principal component analysis (PCA) and multivariate statistical analysis (MSA) to classify subtomograms by filament straightness and similar helical parameters. The PCA was performed on wedge-masked difference (WMD) maps (Heumann et al., 2011) with calculations implemented in MATLAB using code adapted from PEET (Heumann et al., 2011) and Dynamo packages, and MSA also implemented in MATLAB using code adapted from I3 (Winkler et al., 2009). Movies detailing the variability related to each Eigenvolume from MSA classification were generated using Eigen-filtering / reconstruction methods, and similar movies from WMD classifications were generated by producing class averages sorted by determined Eigencoefficients. Improved class averages allowed for recalculation of helical parameters and further sub-boxing as well as determining the filament polarity. Specifically, the sub-box poses and positions were determined by autocorrelation of the reference after rotation along the filament axis, which yielded a helical symmetry with a rise of $51.5 \AA$ and rotation of $29^{\circ}$, and then duplicates within a sphere of diameter $50 \AA$ were removed. Poses were not adjusted from their gold-standard alignment values and the Fourier shell correlation determined resolution was improved to $18.5 \AA$ at the 0.143 threshold. Following the FSC calculation, the half-maps were averaged, filtered to the measured resolution by the determined FSC-curve and sharpened using a heuristically determined B-factor of $-4000 \AA^{2}$ (Rosenthal and Henderson, 2003).

\section{Quantitative analysis of membrane structures and virions}

Tomograms were visually inspected and membrane structures such as single-membrane vesicles and tubes were assigned as single membranes. Double membrane structures were assigned as phagophore-like membranes if they had a clear opening within the tomogram volume (i.e. were cup-shaped), and as double-membrane vesicles if they did not have an opening. Collectively, these two types of double-membrane structures were referred to as autophagy-like membranes. Virus particles were localized and counted in each tomogram with template matching using PyTom (Hrabe et al., 2012). For empty capsids and RNA-loaded virions template matching was performed using respectively the re-sampled, filtered empty capsid (EMD-9644) and mature virion (EMD-9642) cryo-EM structures of the human coxsackievirus A10 (Zhu et al., 2018). The concentration of each structures was obtained by dividing the total number of structures by the volume of the corresponding tomogram. The number of tomograms obtained for all the conditions are listed in the supplementary table S1. The closure of viral capsid intermediates was calculated using IMOD. First, in a central section through the capsid intermediate, the circumference was traced and measured with IMOD drawing tools, then the open length was divided by the circumference of a complete virus particle. This fraction was multiplied by 360 to get the angle of the cone that describes the capsid assembly intermediate.

\section{Freeze substitution}

Poliovirus-infected HeLa cells non-treated and treated with MRT68921 were grown on carboncoated sapphire discs and high-pressure frozen at $6 \mathrm{~h}$ p.i. using a Leica HPM100. Freeze substitution was performed as a variation of the Kukulski protocol (Kukulski et al., 2011). Briefly, sapphire discs placed in adapted carriers were filled with freeze substituent $(0.1 \%$ uranyl acetate in acetone, $1 \% \mathrm{H} 2 \mathrm{O}$ ) and placed in a temperature-controlling AFS2 (Leica) equipped with an FPS robot. In the first step, freeze-substitution occurred at $-90^{\circ} \mathrm{C}$ for $48 \mathrm{~h}$ then the temperature was raised to $-45^{\circ} \mathrm{C}$. The samples were maintained in the freeze substituent at $-45^{\circ} \mathrm{C}$ for $5 \mathrm{~h}$ before washing 3 times with acetone followed by a temperature 
bioRxiv preprint doi: https://doi.org/10.1101/2021.10.06.463375; this version posted October 6,2021 . The copyright holder for this preprint (which was not certified by peer review) is the author/funder, who has granted bioRxiv a license to display the preprint in perpetuity. It is made available under aCC-BY 4.0 International license.

increase and infiltration with increasing concentrations of Lowicryl HM20. Finally, the samples were gradually warmed up to $-25^{\circ} \mathrm{C}$ before infiltrating 3 times with $100 \%$ Lowicryl and UVpolymerized for $48 \mathrm{~h}$ at $-25^{\circ} \mathrm{C}$. Polymerization then continued for another $24 \mathrm{~h}$ at room temperature. The embedded samples were sectioned with a diamond knife (DiATOME-90) to slices of 60-120 nm thickness by using ultramicrotome (Reichart ULTRACUT S). Imaging was performed in FEI Talos electron microscope operating at $120 \mathrm{kV}$. Grids were examined at a Talos L120C (FEI, Eindhoven, The Netherlands) operating at 120kV. Micrographs were acquired with a Ceta 16M CCD camera (FEI, Eindhoven, The Netherlands) using TEM Image \& Analysis software ver. 4.17 (FEl, Eindhoven, The Netherlands).

\section{Confocal microscopy analysis}

HeLa wildtype (WT), LC3 $3 K O$ and GAB $3 K O$ cells were infected with PV for $1 \mathrm{~h}$ at MOI 5 in serum free media, washed and kept in $2 \%$ FCS DMEM/high glucose for $3 \mathrm{~h}$ or $6 \mathrm{~h}$. Cells were fixed in 4\% paraformaldehyde (PFA)/phosphate buffer solution (PBS) for 10 min at room temperature. Primary and secondary antibody incubations were carried out in PBS $/ 10 \% \mathrm{FBS}$ supplemented with saponin at $0.2 \%$ for $1 \mathrm{~h}$ at room temperature. Cells were rinsed twice in PBS, twice in water and mounted with Dapi Fluoromount-G (Electron Microscopy Science). Image acquisition was performed using a LSM780 confocal microscope (Carl Zeiss) with a $63 X / 1.4$ NA oil objective or a 40X/1.4 NA oil objective. Cell numbers and individual cells respective mean fluorescence intensities and area were obtained using ImageJ.

\section{Virus titration analysis of cell supernatants}

Extracellular medium was collected from infected cell cultures and serially diluted in 96 well plates $\left(10^{-1}\right.$ to $\left.10^{-8}\right)$. Dilutions were subsequently used to inoculate in triplicates HeLa WT cells seeded at $6 \times 10^{4}$ cells/well in 96 -well plates. Cells were incubated at $37^{\circ} \mathrm{C}$ for $44 \mathrm{~h}$, fixed with $10 \%$ paraformaldehyde and stained with crystal violet. TCID50/ml was calculated using the Spearman \& Kärber algorithm.

\section{Vesicle isolation}

HeLa wildtype (WT), LC3 $3 K O$ and GAB $3 K O$ cells were infected with PV for $1 \mathrm{~h}$ at MOI 5, washed and kept in serum-free DMEM/high glucose for $8 \mathrm{~h}$. Supernatants obtained from one well of a 6 -well plate $(1.5 \mathrm{~mL}, \sim 500000$ cells) were harvested and centrifuged at $1000 \mathrm{~g}$ for $10 \mathrm{~min}$, then at $20000 \mathrm{~g}$ for $30 \mathrm{~min}$. Pellets were either resuspended in $1 \mathrm{X}$ loading buffer and analyzed by Western Blot, or resuspend in RNA lysis buffer and processed for RT-PCR.

\section{Quantitative (q) PCR analysis}

Cell supernatants and cell lysates were harvested at specific time points and lysed using RNA lysis buffer provided in the RNA isolation kit (Quick-RNA Microprep Kit, Zymo Research). RNA isolation was performed as per the manufacturer's instructions and CDNA was prepared using Thermo Scientific Maxima First Strand cDNA Synthesis Kit for RT-qPCR (Fisher Scientific). RT-PCR was performed using iTaq Universal SYBR® Green Supermix (BioRad) in Roche LightCycler 96 system (Roche), using the following thermal cycling conditions: $95^{\circ} \mathrm{C}$ for $90 \mathrm{~s}$, 40 cycles at $95^{\circ} \mathrm{C}$ for $10 \mathrm{sec}, 57^{\circ} \mathrm{C}$ for $10 \mathrm{sec}$ and $72^{\circ} \mathrm{C}$ for $110 \mathrm{sec}$. The samples were run in duplicate for each data point and each experiment.

\section{QUANTIFICATION AND STATISTICAL ANALYSIS}

Data and statistical analysis were performed using Prism (GraphPad Software Inc., USA). Details about replicates, statistical test used, exact values of $n$, what $n$ represents, and dispersion and precision measures used can be found in figures and corresponding figure legends. Values of $p<0.05$ were considered significant. 
bioRxiv preprint doi: https://doi.org/10.1101/2021.10.06.463375; this version posted October 6,2021 . The copyright holder for this preprint

\section{References}

Bago, R., Malik, N., Munson, M.J., Prescott, A.R., Davies, P., Sommer, E., Shpiro, N., Ward, R., Cross, D., Ganley, I.G., et al. (2014). Characterization of VPS34-IN1, a selective inhibitor of Vps34, reveals that the phosphatidylinositol 3-phosphate-binding SGK3 protein kinase is a downstream target of class III phosphoinositide 3-kinase. Biochem J 463, 413-427.

Basavappa, R., Syed, R., Flore, O., Icenogle, J.P., Filman, D.J., and Hogle, J.M. (1994). Role and mechanism of the maturation cleavage of VPO in poliovirus assembly: structure of the empty capsid assembly intermediate at 2.9 A resolution. Protein Sci 3, 1651-1669.

Bou, J.V., Geller, R., and Sanjuan, R. (2019). Membrane-Associated Enteroviruses Undergo Intercellular Transmission as Pools of Sibling Viral Genomes. Cell Rep 29, 714-723 e714.

Castano-Diez, D., Kudryashev, M., Arheit, M., and Stahlberg, H. (2012). Dynamo: a flexible, user-friendly development tool for subtomogram averaging of cryo-EM data in highperformance computing environments. J Struct Biol 178, 139-151.

Castano-Diez, D., Kudryashev, M., and Stahlberg, H. (2017). Dynamo Catalogue: Geometrical tools and data management for particle picking in subtomogram averaging of cryo-electron tomograms. J Struct Biol 197, 135-144.

Chandler-Bostock, R., Mata, C.P., Bingham, R.J., Dykeman, E.C., Meng, B., Tuthill, T.J., Rowlands, D.J., Ranson, N.A., Twarock, R., and Stockley, P.G. (2020). Assembly of infectious enteroviruses depends on multiple, conserved genomic RNA-coat protein contacts. PLoS Pathog 16, e1009146.

Chen, S., McMullan, G., Faruqi, A.R., Murshudov, G.N., Short, J.M., Scheres, S.H., and Henderson, R. (2013). High-resolution noise substitution to measure overfitting and validate resolution in $3 \mathrm{D}$ structure determination by single particle electron cryomicroscopy. Ultramicroscopy 135, 24-35.

Chen, Y.H., Du, W., Hagemeijer, M.C., Takvorian, P.M., Pau, C., Cali, A., Brantner, C.A., Stempinski, E.S., Connelly, P.S., Ma, H.C., et al. (2015). Phosphatidylserine vesicles enable efficient en bloc transmission of enteroviruses. Cell 160, 619-630.

Corona, A.K., Saulsbery, H.M., Corona Velazquez, A.F., and Jackson, W.T. (2018). Enteroviruses Remodel Autophagic Trafficking through Regulation of Host SNARE Proteins to Promote Virus Replication and Cell Exit. Cell Rep 22, 3304-3314.

Corona Velazquez, A., Corona, A.K., Klein, K.A., and Jackson, W.T. (2018). Poliovirus induces autophagic signaling independent of the ULK1 complex. Autophagy 14, 1201-1213.

Feng, Z., Hensley, L., McKnight, K.L., Hu, F., Madden, V., Ping, L., Jeong, S.H., Walker, C., Lanford, R.E., and Lemon, S.M. (2013). A pathogenic picornavirus acquires an envelope by hijacking cellular membranes. Nature 496, 367-371.

Förster, F., Medalia, O., Zauberman, N., Baumeister, W., and Fass, D. (2005). Retrovirus envelope protein complex structure in situ studied by cryo-electron tomography. Proceedings of the National Academy of Sciences of the United States of America 102, 4729-4734.

Gatica, D., Lahiri, V., and Klionsky, D.J. (2018). Cargo recognition and degradation by selective autophagy. Nat Cell Biol 20, 233-242.

Hagen, C., Dent, K.C., Zeev-Ben-Mordehai, T., Grange, M., Bosse, J.B., Whittle, C., Klupp, B.G., Siebert, C.A., Vasishtan, D., Bauerlein, F.J., et al. (2015). Structural Basis of Vesicle Formation at the Inner Nuclear Membrane. Cell 163, 1692-1701.

Heumann, J.M., Hoenger, A., and Mastronarde, D.N. (2011). Clustering and variance maps for cryo-electron tomography using wedge-masked differences. J Struct Biol 175, 288-299.

Hrabe, T., Chen, Y., Pfeffer, S., Cuellar, L.K., Mangold, A.V., and Forster, F. (2012). PyTom: a python-based toolbox for localization of macromolecules in cryo-electron tomograms and subtomogram analysis. J Struct Biol 178, 177-188.

Hsu, N.Y., Inytska, O., Belov, G., Santiana, M., Chen, Y.H., Takvorian, P.M., Pau, C., van der Schaar, H., Kaushik-Basu, N., Balla, T., et al. (2010). Viral reorganization of the secretory pathway generates distinct organelles for RNA replication. Cell 141, 799-811.

Jackson, W.T. (2014). Poliovirus-induced changes in cellular membranes throughout infection. Curr Opin Virol 9, 67-73. 
bioRxiv preprint doi: https://doi.org/10.1101/2021.10.06.463375; this version posted October 6,2021 . The copyright holder for this preprint

Jiang, P., Liu, Y., Ma, H.C., Paul, A.V., and Wimmer, E. (2014). Picornavirus morphogenesis. Microbiol Mol Biol Rev 78, 418-437.

Klein, S., Cortese, M., Winter, S.L., Wachsmuth-Melm, M., Neufeldt, C.J., Cerikan, B., Stanifer, M.L., Boulant, S., Bartenschlager, R., and Chlanda, P. (2020). SARS-CoV-2 structure and replication characterized by in situ cryo-electron tomography. Nature communications 11 , 5885.

Kremer, J.R., Mastronarde, D.N., and McIntosh, J.R. (1996). Computer visualization of threedimensional image data using IMOD. J Struct Biol 116, 71-76.

Kukulski, W., Schorb, M., Welsch, S., Picco, A., Kaksonen, M., and Briggs, J.A. (2011). Correlated fluorescence and 3D electron microscopy with high sensitivity and spatial precision. The Journal of cell biology 192, 111-119.

Limpens, R.W., van der Schaar, H.M., Kumar, D., Koster, A.J., Snijder, E.J., van Kuppeveld, F.J., and Barcena, M. (2011). The transformation of enterovirus replication structures: a threedimensional study of single- and double-membrane compartments. mBio 2.

Liu, Y., Wang, C., Mueller, S., Paul, A.V., Wimmer, E., and Jiang, P. (2010). Direct interaction between two viral proteins, the nonstructural protein $2 \mathrm{C}$ and the capsid protein VP3, is required for enterovirus morphogenesis. PLoS Pathog 6, e1001066.

Mastronarde, D.N. (2005). Automated electron microscope tomography using robust prediction of specimen movements. J Struct Biol 152, 36-51.

Mi, N., Chen, Y., Wang, S., Chen, M., Zhao, M., Yang, G., Ma, M., Su, Q., Luo, S., Shi, J., et al. (2015). CapZ regulates autophagosomal membrane shaping by promoting actin assembly inside the isolation membrane. Nat Cell Biol 17, 1112-1123.

Miller, S., and Krijnse-Locker, J. (2008). Modification of intracellular membrane structures for virus replication. Nature reviews 6, 363-374.

Mohamud, Y., Shi, J., Qu, J., Poon, T., Xue, Y.C., Deng, H., Zhang, J., and Luo, H. (2018). Enteroviral Infection Inhibits Autophagic Flux via Disruption of the SNARE Complex to Enhance Viral Replication. Cell Rep 22, 3292-3303.

Mutsafi, Y., and Altan-Bonnet, N. (2018). Enterovirus Transmission by Secretory Autophagy. Viruses 10.

Nguyen, T.N., Padman, B.S., Usher, J., Oorschot, V., Ramm, G., and Lazarou, M. (2016). Atg8 family LC3/GABARAP proteins are crucial for autophagosome-lysosome fusion but not autophagosome formation during PINK1/Parkin mitophagy and starvation. The Journal of cell biology 215, 857-874.

Nickell, S., Förster, F., Linaroudis, A., Del Net, W., Beek, F., Hegerl, R., Baumeister, W., and Plitzko, J.M. (2005). TOM software toolbox: acquisition and analysis for electron tomography. J Struct Biol 149, 227-234.

Nugent, C.I., Johnson, K.L., Sarnow, P., and Kirkegaard, K. (1999). Functional coupling between replication and packaging of poliovirus replicon RNA. J Virol 73, 427-435.

Paul, D., and Bartenschlager, R. (2013). Architecture and biogenesis of plus-strand RNA virus replication factories. World journal of virology 2, 32-48.

Petherick, K.J., Conway, O.J., Mpamhanga, C., Osborne, S.A., Kamal, A., Saxty, B., and Ganley, I.G. (2015). Pharmacological inhibition of ULK1 kinase blocks mammalian target of rapamycin (mTOR)-dependent autophagy. J Biol Chem 290, 11376-11383.

Pettersen, E.F., Goddard, T.D., Huang, C.C., Couch, G.S., Greenblatt, D.M., Meng, E.C., and Ferrin, T.E. (2004). UCSF Chimera--a visualization system for exploratory research and analysis. Journal of computational chemistry 25, 1605-1612.

Pfister, T., Pasamontes, L., Troxler, M., Egger, D., and Bienz, K. (1992). Immunocytochemical localization of capsid-related particles in subcellular fractions of poliovirus-infected cells. Virology 188, 676-684.

Rigort, A., Gunther, D., Hegerl, R., Baum, D., Weber, B., Prohaska, S., Medalia, O., Baumeister, W., and Hege, H.C. (2012). Automated segmentation of electron tomograms for a quantitative description of actin filament networks. J Struct Biol 177, 135-144.

Robinson, S.M., Tsueng, G., Sin, J., Mangale, V., Rahawi, S., Mclntyre, L.L., Williams, W., Kha, N., Cruz, C., Hancock, B.M., et al. (2014). Coxsackievirus B exits the host cell in shed microvesicles displaying autophagosomal markers. PLoS Pathog 10, e1004045. 
bioRxiv preprint doi: https://doi.org/10.1101/2021.10.06.463375; this version posted October 6,2021 . The copyright holder for this preprint (which was not certified by peer review) is the author/funder, who has granted bioRxiv a license to display the preprint in perpetuity. It is made available under aCC-BY 4.0 International license.

Rohou, A., and Grigorieff, N. (2015). CTFFIND4: Fast and accurate defocus estimation from electron micrographs. J Struct Biol 192, 216-221.

Rombaut, B., Vrijsen, R., Delgadillo, R., Vanden Berghe, D., and Boeye, A. (1985). Characterization and assembly of poliovirus-related $45 \mathrm{~S}$ particles. Virology 146, 111-119.

Romero-Brey, I., and Bartenschlager, R. (2014). Membranous replication factories induced by plus-strand RNA viruses. Viruses 6, 2826-2857.

Rosenthal, P.B., and Henderson, R. (2003). Optimal determination of particle orientation, absolute hand, and contrast loss in single-particle electron cryomicroscopy. J Mol Biol 333, 721-745.

Roulin, P.S., Lotzerich, M., Torta, F., Tanner, L.B., van Kuppeveld, F.J., Wenk, M.R., and Greber, U.F. (2014). Rhinovirus uses a phosphatidylinositol 4-phosphate/cholesterol countercurrent for the formation of replication compartments at the ER-Golgi interface. Cell Host Microbe 16, 677-690.

Schaffer, M., Mahamid, J., Engel, B.D., Laugks, T., Baumeister, W., and Plitzko, J.M. (2017). Optimized cryo-focused ion beam sample preparation aimed at in situ structural studies of membrane proteins. J Struct Biol 197, 73-82.

Sobo, K., Stuart, A.D., Rubbia-Brandt, L., Brown, T.D.K., and McKee, T.A. (2012). Echovirus 11 infection induces dramatic changes in the actin cytoskeleton of polarized Caco-2 cells. J Gen Virol 93, 475-487.

Su, R.T., and Taylor, M.W. (1976). Morphogenesis of picornaviruses: characterization and assembly of bovine enterovirus subviral particles. J Gen Virol 30, 317-328.

Taylor, M.P., and Kirkegaard, K. (2007). Modification of cellular autophagy protein LC3 by poliovirus. J Virol 81, 12543-12553.

Turk, M., and Baumeister, W. (2020). The promise and the challenges of cryo-electron tomography. FEBS Lett 594, 3243-3261.

Turonova, B., Schur, F.K.M., Wan, W., and Briggs, J.A.G. (2017). Efficient 3D-CTF correction for cryo-electron tomography using NovaCTF improves subtomogram averaging resolution to 3.4A. J Struct Biol 199, 187-195.

Twarock, R., Bingham, R.J., Dykeman, E.C., and Stockley, P.G. (2018). A modelling paradigm for RNA virus assembly. Curr Opin Virol 31, 74-81.

van der Linden, L., Wolthers, K.C., and van Kuppeveld, F.J. (2015). Replication and Inhibitors of Enteroviruses and Parechoviruses. Viruses 7, 4529-4562.

Vance, L.M., Moscufo, N., Chow, M., and Heinz, B.A. (1997). Poliovirus 2C region functions during encapsidation of viral RNA. J Virol 71, 8759-8765.

Wan, W., Kolesnikova, L., Clarke, M., Koehler, A., Noda, T., Becker, S., and Briggs, J.A.G. (2017). Structure and assembly of the Ebola virus nucleocapsid. Nature 551, 394-397.

Winkler, H., Zhu, P., Liu, J., Ye, F., Roux, K.H., and Taylor, K.A. (2009). Tomographic subvolume alignment and subvolume classification applied to myosin $\mathrm{V}$ and SIV envelope spikes. J Struct Biol 165, 64-77.

Wolff, G., Limpens, R., Zevenhoven-Dobbe, J.C., Laugks, U., Zheng, S., de Jong, A.W.M., Koning, R.I., Agard, D.A., Grunewald, K., Koster, A.J., et al. (2020a). A molecular pore spans the double membrane of the coronavirus replication organelle. Science (New York, NY 369, 1395-1398.

Wolff, G., Melia, C.E., Snijder, E.J., and Barcena, M. (2020b). Double-Membrane Vesicles as Platforms for Viral Replication. Trends Microbiol 28, 1022-1033.

Xiao, X., Lei, X., Zhang, Z., Ma, Y., Qi, J., Wu, C., Xiao, Y., Li, L., He, B., and Wang, J. (2017). Enterovirus 3A Facilitates Viral Replication by Promoting Phosphatidylinositol 4-Kinase IllbetaACBD3 Interaction. J Virol 91.

Xiong, Q., Morphew, M.K., Schwartz, C.L., Hoenger, A.H., and Mastronarde, D.N. (2009). CTF determination and correction for low dose tomographic tilt series. J Struct Biol 168, 378-387.

Yang, J.E., Rossignol, E.D., Chang, D., Zaia, J., Forrester, I., Raja, K., Winbigler, H., Nicastro, D., Jackson, W.T., and Bullitt, E. (2020). Complexity and ultrastructure of infectious extracellular vesicles from cells infected by non-enveloped virus. Scientific reports 10, 7939. 
Zheng, S.Q., Palovcak, E., Armache, J.P., Verba, K.A., Cheng, Y., and Agard, D.A. (2017). MotionCor2: anisotropic correction of beam-induced motion for improved cryo-electron microscopy. Nat Methods 14, 331-332.

Zhu, L., Sun, Y., Fan, J., Zhu, B., Cao, L., Gao, Q., Zhang, Y., Liu, H., Rao, Z., and Wang, X. (2018). Structures of Coxsackievirus A10 unveil the molecular mechanisms of receptor binding and viral uncoating. Nature communications 9, 4985.

Zila, V., Margiotta, E., Turonova, B., Muller, T.G., Zimmerli, C.E., Mattei, S., Allegretti, M., Borner, K., Rada, J., Muller, B., et al. (2021). Cone-shaped HIV-1 capsids are transported through intact nuclear pores. Cell 184, 1032-1046 e1018. 

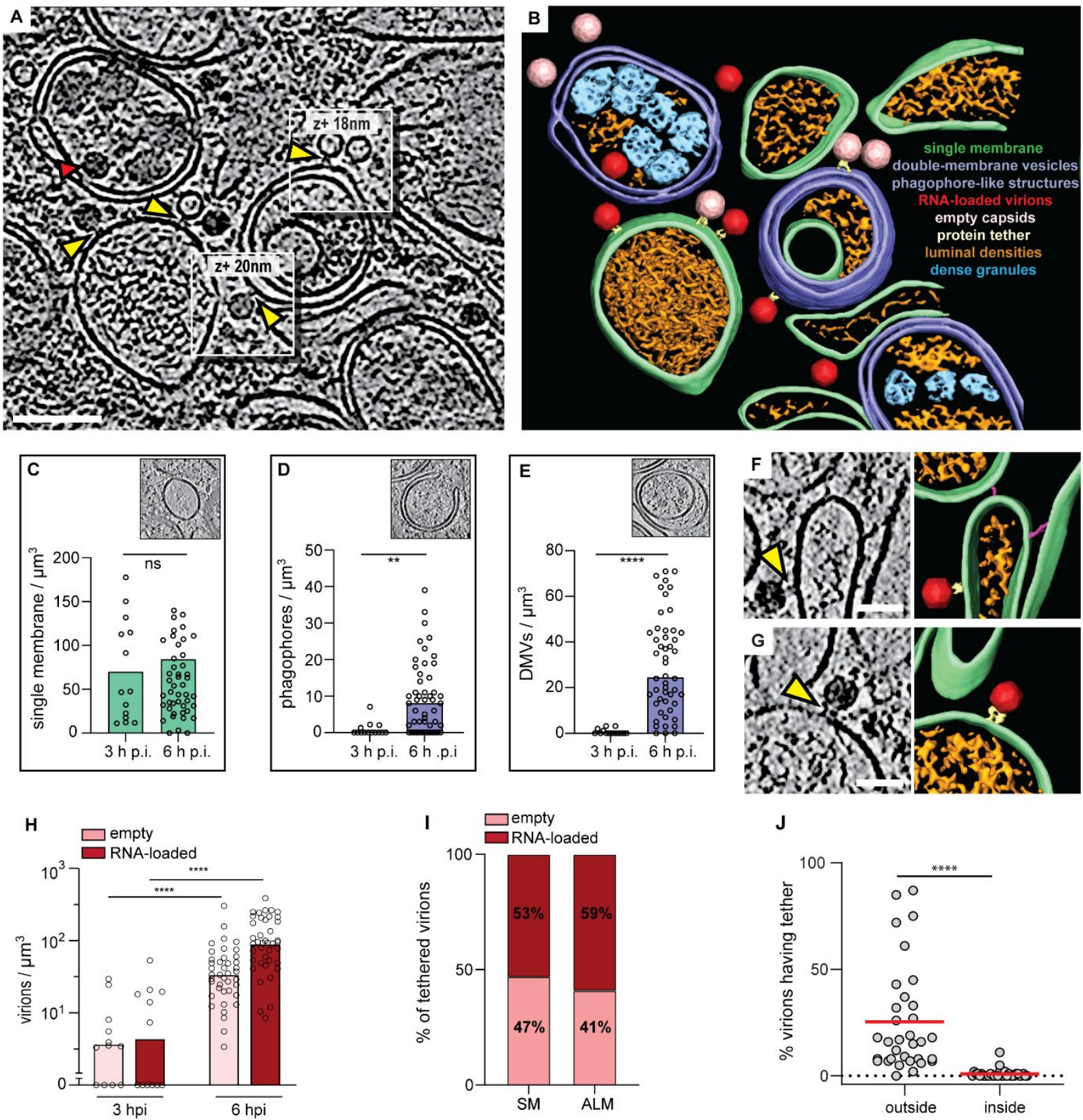

Figure 1: Cryo-electron tomography allows the visualization of poliovirus replication and assembly sites in situ. (A) Slice through a representative cryo-electron tomogram of a lamella milled through a PV-infected cell at $6 \mathrm{~h}$ p.i., revealing PV-induced SM (Single Membranes) and ALM (Autophagy-Like Membranes) proliferation. Yellow arrowheads indicate densities tethering intracellular empty capsids and darker RNA-loaded virions to membranes. Red arrowhead indicates a virion enclosed inside a DMV (Double-Membrane Vesicle), proximal but not tethered to the membrane. (B) Segmentation of the tomogram presented in (A). Color labels are defined for each structure. Empty capsids (pink) and RNA-loaded (red) virions are represented by their subtomogram averages. (C-E) Scatter plots with bars representing the mean concentration of SM structures (C), phagophore-like structures (D), and DMVs (E), observed in cryo-tomograms of $3 \mathrm{~h} \mathrm{p.i.} \mathrm{and} 6 \mathrm{~h} \mathrm{p.i.} \mathrm{Insets:} \mathrm{slices} \mathrm{through}$ different tomograms showing the type of membrane for each graph. (F-G) Slices through a tomogram of a PV-infected cell at $3 \mathrm{~h} \mathrm{p.i.} \mathrm{and} \mathrm{their} \mathrm{corresponding} \mathrm{3D} \mathrm{segmentation} \mathrm{showing} \mathrm{RNA-loaded} \mathrm{virions}$ tethered to the SM (yellow arrowheads). $(\mathrm{H})$ Concentration of intracellular empty capsids and RNAloaded virions in tomograms at $3 \mathrm{~h}$ p.i. and $6 \mathrm{~h}$ p.i., as measured by template matching. (I) Percentage of empty and RNA-loaded virions on SM and ALM. (J) Percentage of virions on the outside and inside of ALM having a visible tether to a membrane. In all graphs, each dot corresponds to one tomogram (see also Supplementary table 2). Statistical significance was assessed by unpaired two-tailed Student's $\mathrm{t}$ test; ${ }^{* *} p<0,01$ and ${ }^{* * * *} p<0,0001$. Scale bars: (A) $100 \mathrm{~nm}$, (G-F) $50 \mathrm{~nm}$. 

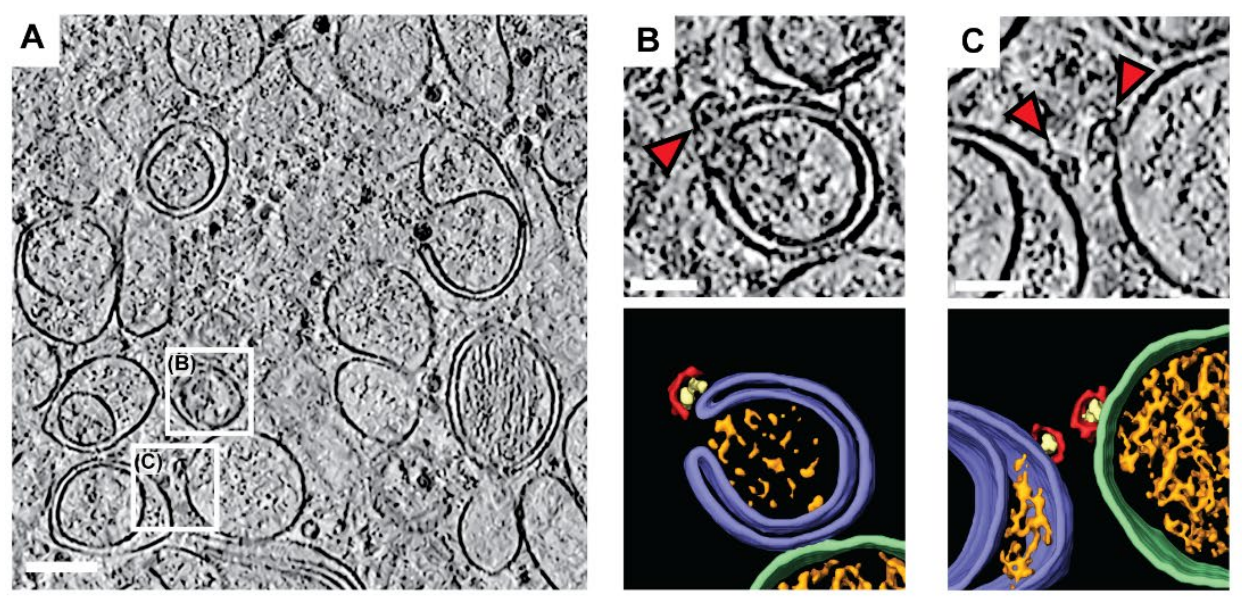

capsid intermediates localization
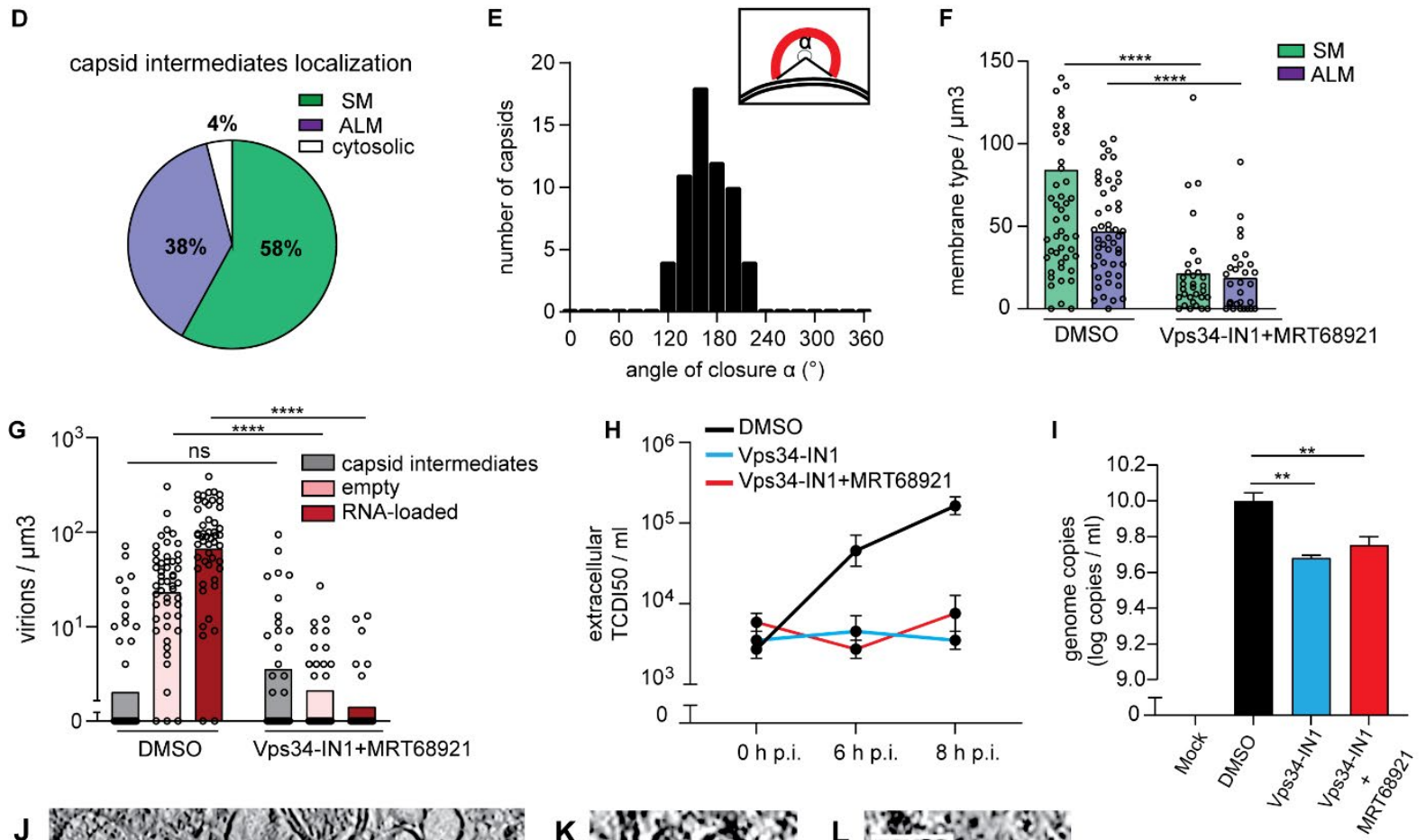

$\mathbf{F}$

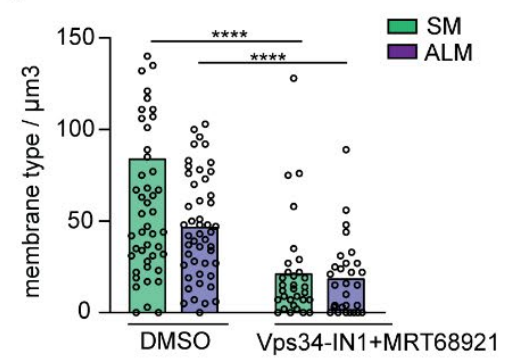

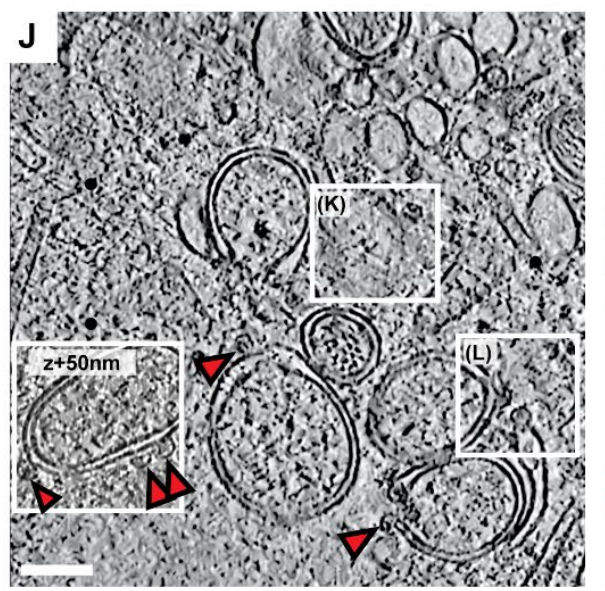
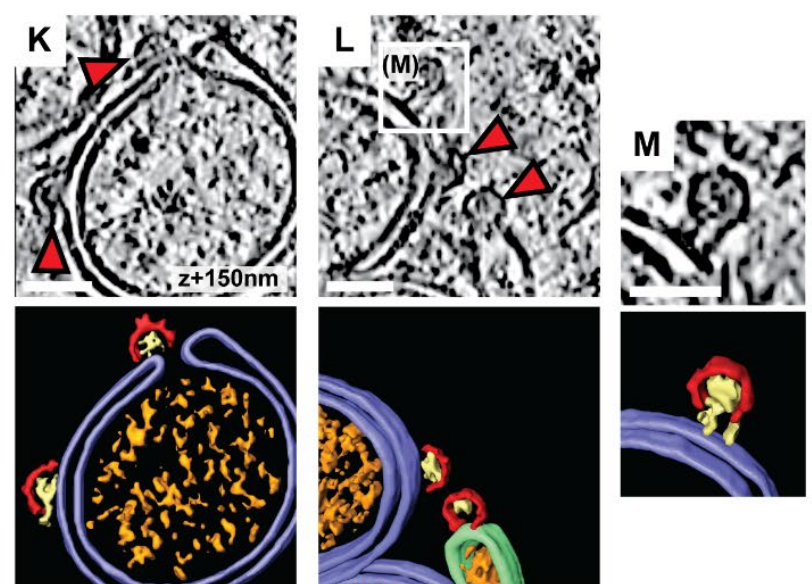

Figure 2: Capsid assembly happens on membranes and is stalled upon VPS34 inhibition. (A) Cryo-electron tomogram of a PV-infected cell at $6 \mathrm{~h}$ p.i. White boxes indicate areas with capsid assembly intermediates. (B-C) Magnified views of boxes in (A) with capsid intermediates indicated by red arrowheads, and their corresponding 3D segmentations showing capsid assembly intermediates (red) containing luminal densities (yellow), associated with autophagy-like membranes (ALMs, purple) and a single-membrane vesicle (SM, green). (D) Percentage of capsid assembly intermediates found on SMs, ALMs or not associated with membranes, as counted in 15 tomograms at $6 \mathrm{~h}$ p.i. (E) Distribution of capsid intermediate closures $(\alpha)$, as defined in the inset, measured at $6 \mathrm{~h}$ p.i. Average closure was $169^{\circ}$ 
bioRxiv preprint doi: $h t t p s: / / d o i . o r g / 10.1101 / 2021.10 .06 .463375$; this version posted October 6, 2021. The copyright holder for this preprint (which was not certified by peer review) is the author/funder, who has granted bioRxiv a license to display the preprint in perpetuity. It is made available under aCC-BY 4.0 International license.

$\left(\mathrm{SD}=26^{\circ}, \mathrm{N}=51\right)$. $(\mathrm{F})$ Concentration of SMs and ALMs measured in DMSO and Vps34-IN1 + MRT68921 treated cells at $6 \mathrm{~h}$ p.i. (G) Concentration of intracellular capsid intermediates, empty capsids and RNAloaded virions in DMSO and Vps34-IN1 + MRT68921 treated cells at $6 \mathrm{~h} \mathrm{p.i.} \mathrm{(F-G)} \mathrm{Each} \mathrm{dot} \mathrm{corresponds}$ to one tomogram, bars represent the averages (see also Supplementary table 2). (H) Released virus titer at 0,6 , and $8 \mathrm{~h}$ p.i. in cells treated with DMSO, Vps34-IN1, and Vps34-IN1 + MRT68921. (I) Intracellular viral RNA copies measured at $6 \mathrm{~h}$ p.i. in cells treated with DMSO, Vps34-IN1 and Vps34IN1 + MRT68921. (H-I) Bars represent the means of biological triplicates \pm SEM. $(\mathrm{J})$ Cryo-electron tomogram of a PV-infected cell co-treated with Vps34-IN1 and MRT68921 at $6 \mathrm{~h}$ p.i. White boxes indicate areas with capsid assembly intermediates. (K-L) Magnified views of boxes in $(\mathrm{J})$ and their corresponding segmentations. Labeling and colors as in (B-C). (M) Further magnification of box in (L) showing a near-complete capsid tethered to a double-membrane vesicle. Statistical significance by unpaired two-tailed Student's t test; ${ }^{*} p<0,05 ;{ }^{* *} p<0,01$ and ${ }^{* * * *} p<0,0001$. Scale bars: (A and J) $100 \mathrm{~nm}$, (B-C and K-M) $50 \mathrm{~nm}$. 

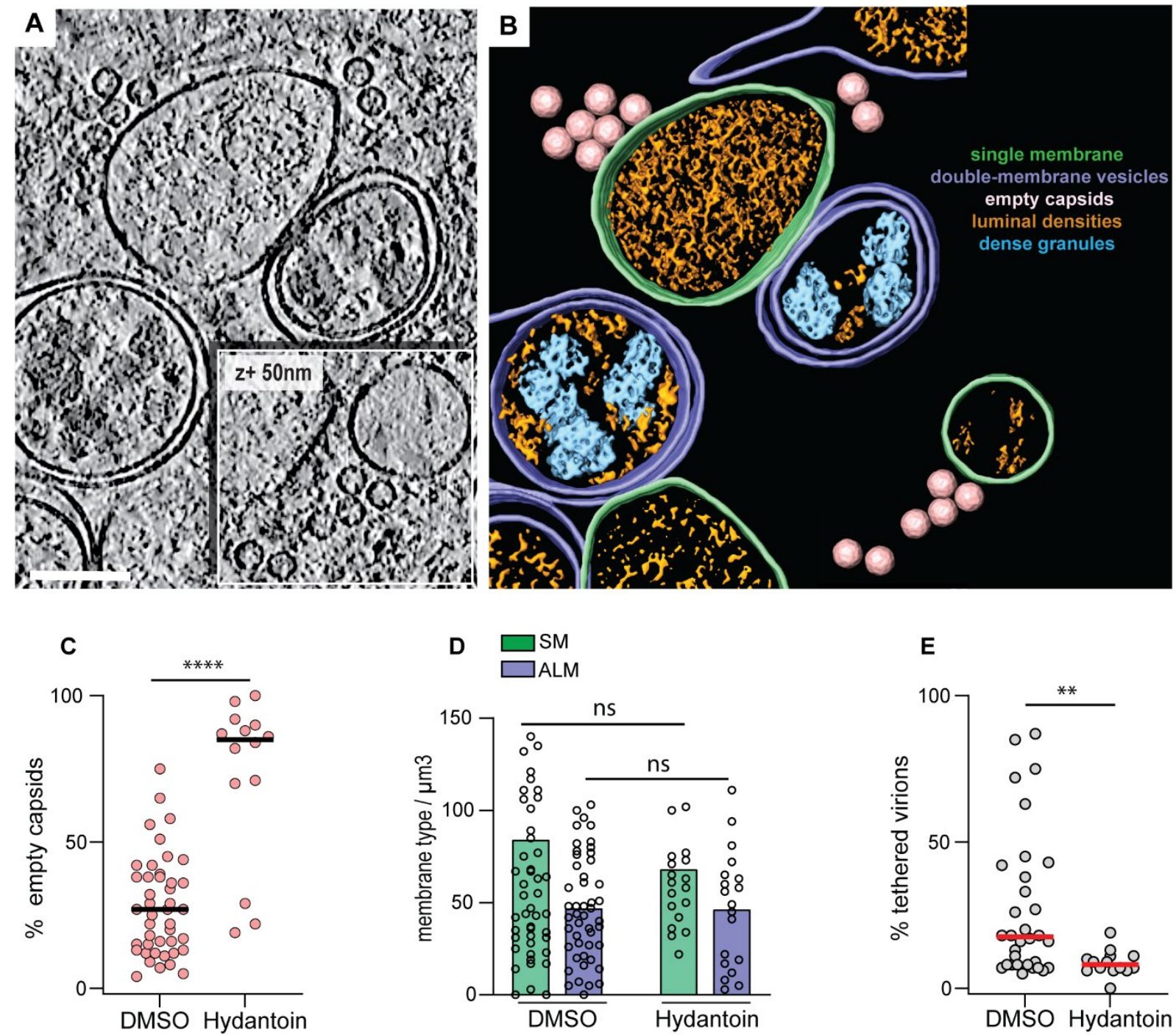

Figure 3: Untethering capsids from membranes prevents RNA loading. (A) Cryo-electron tomogram of a PV-infected, Hydantoin-treated cell at $6 \mathrm{~h}$ p.i., containing several empty capsids which are not tethered to the surrounding membranes. (B) Segmentation of the tomogram in (A). Color labels are defined for each structure and empty capsids are represented by their subtomogram average. (C) Percentage of empty capsids in tomograms of DMSO and Hydantoin-treated cells at $6 \mathrm{~h}$ p.i., as measured by template matching. Horizontal lines represent the average. (D) Scatter plot with bars representing the mean concentration of SM and ALM measured in Hydantoin-treated cells at $6 \mathrm{~h}$ p.i. compared to DMSO-treated cells. (E) Percentage of tethered virions in DMSO and Hydantoin as observed in $6 \mathrm{~h}$ p.i. cryo-tomograms. Horizontal lines represent the average. In all graphs, each dot corresponds to one tomogram analyzed (see also Supplementary table 2). Statistical significance by unpaired two-tailed Student's t test; ${ }^{* *} p<0,01$ and ${ }^{* * * *} p<0,0001$. Scale bar $100 \mathrm{~nm}$. 

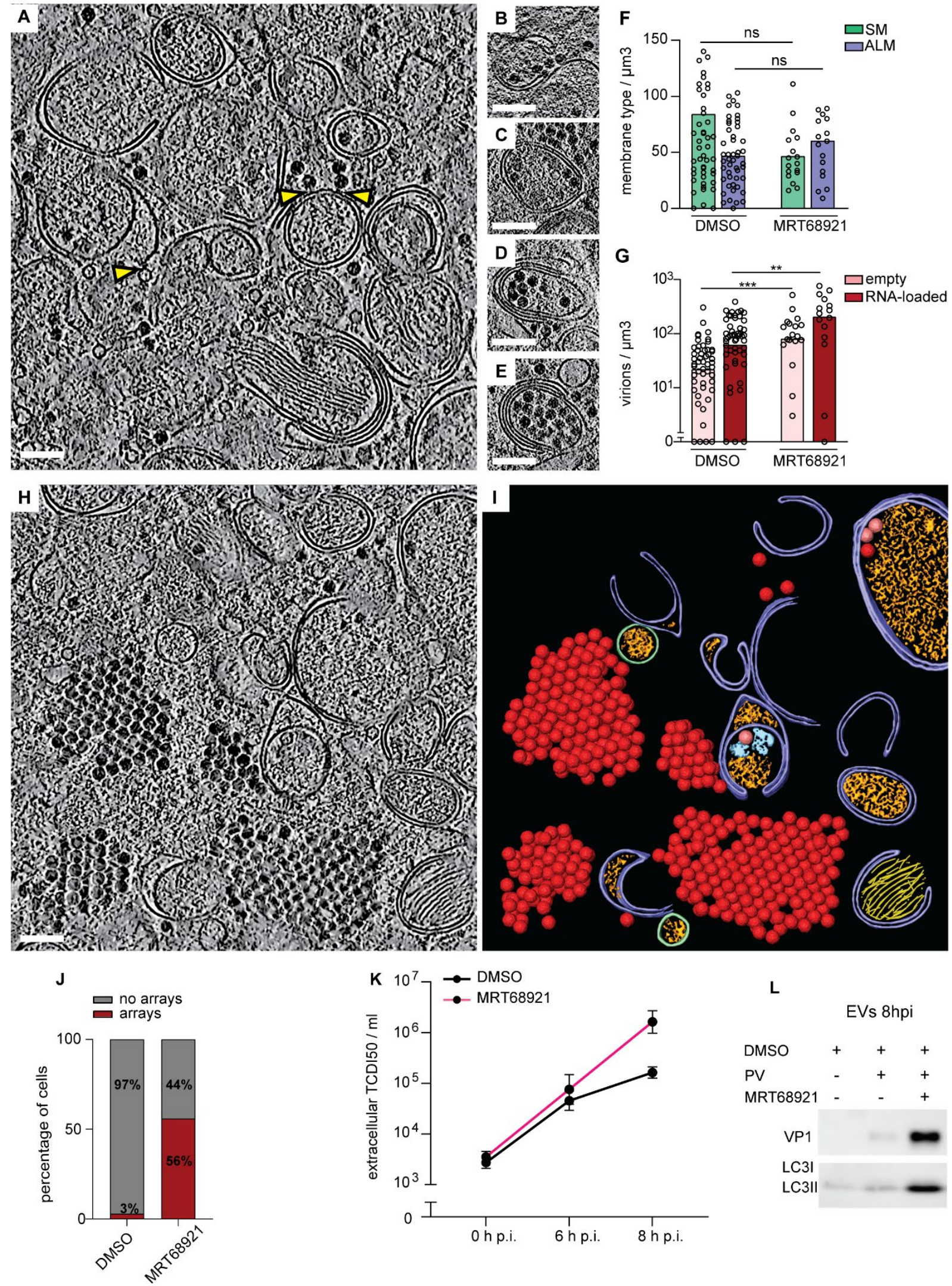

Figure 4: Inhibition of ULK1/ULK2 induces formation of intracellular virus arrays and increases infectious virus release. (A-E) Cryo-electron tomograms of MRT68921-treated, PV-infected cells at 6 $h$ p.i., showing a larger area overview $(A)$ as well as several examples of virion recruitment to ALMs (BE). (F-G) Concentration of SMs vs. ALMs (F) and concentration of intracellular empty vs. RNA-loaded virions (G) observed in cryo-tomograms of MRT68921 treated cells compared to untreated cells at $6 \mathrm{~h}$ p.i. Each dot corresponds to one tomogram analyzed and bars represent the mean (see also 
Supplementary table 2). (H) Cryo-electron tomogram of an MRT68921-treated, PV-infected cell containing cytoplasmic virion arrays. (I) Segmentation of the tomogram in $(\mathrm{H})$. Virions are represented by their subtomogram averages. Colors are as in Fig. 1B. Protein filament bundles are shown in yellow. (J) Percentage of cells containing virus arrays in DMSO and MRT68921 treated cells as measured from freeze-substituted sections. (K) Time course measurement of extracellular PV titers obtained from MRT68921 and DMSO-treated cells. Error bars represent the means of biological triplicates \pm SEM. (L) Western blot revealing the release of the LC3B-positive virus-containing vesicles at $8 \mathrm{~h}$ p.i. Statistical significance by unpaired two-tailed Student's t test; ${ }^{* *} p<0,01$ and ${ }^{* * *} p<0,001$. Scale bars $100 \mathrm{~nm}$. 

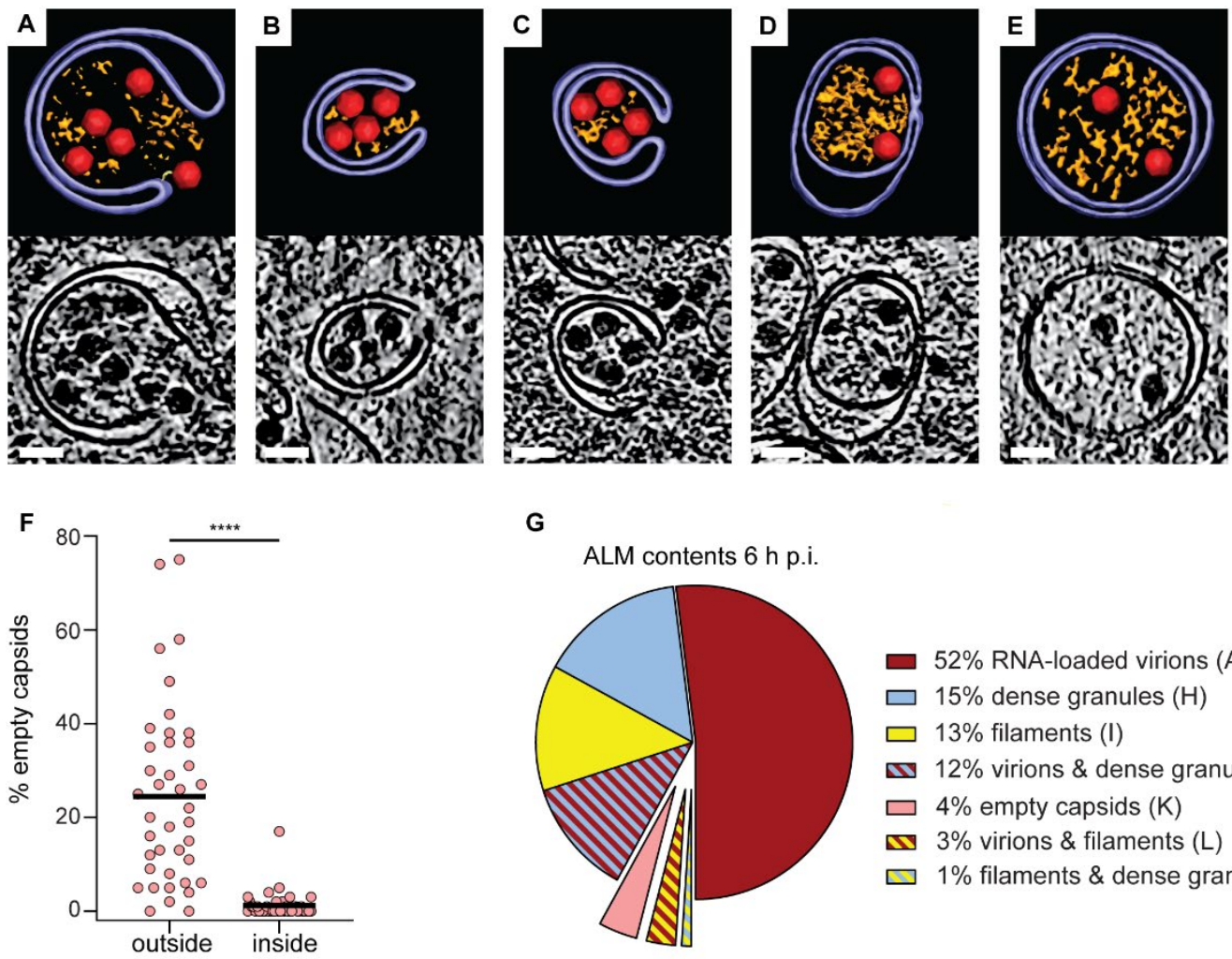

G
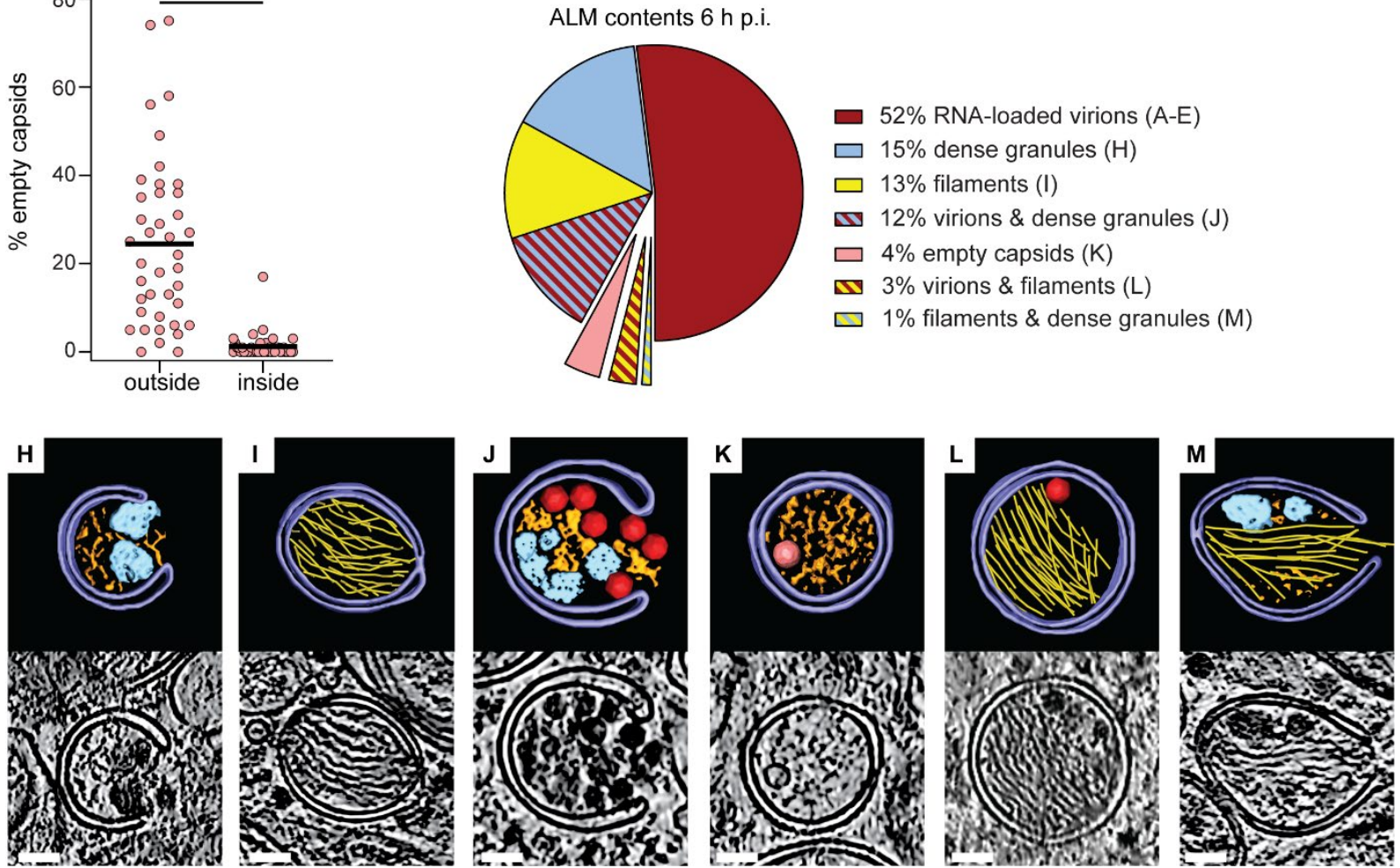

Figure 5: Autophagic membranes select and sort their contents in PV-infected cells. (A-E) Tomograms of PV-infected cells at $6 \mathrm{~h}$ p.i. showing different stages of engulfment of RNA-loaded virions by ALMs, including initial recruitment to phagophores $(A-C)$ and enclosure in DMVs (D-E). Each panel contains a slice through the tomogram and the corresponding segmentation, colored as in Fig. 1B. (F) Percentage of empty capsids on the outside and inside of ALMs. Each dot corresponds to one tomogram analyzed; horizontal line is the average (see also Supplementary table 2). (G) Relative abundance of seven classes of ALMs by contents (single/mixed), in tomograms of PV-infected cells at $6 \mathrm{~h}$ p.i. (H-M) Segmentations and corresponding tomographic slices of examples of the different ALM classes, as labeled in (G). Colors are as in Fig. 1B. Protein filament bundles are shown in yellow. Statistical significance by unpaired two-tailed Student's $t$ test; ${ }^{* * * *} p<0,0001$. Scale bars $50 \mathrm{~nm}$. 


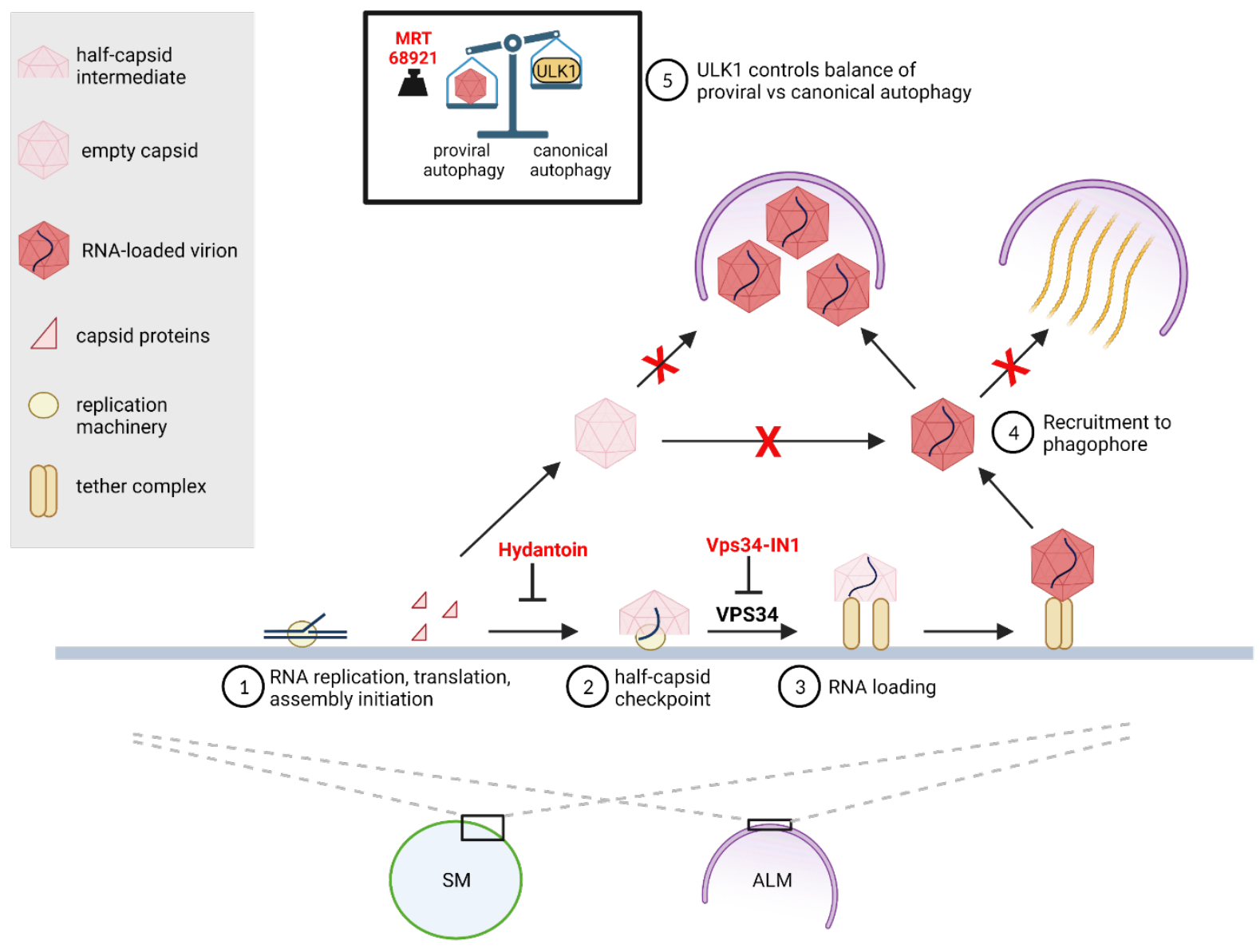

Figure 6: The interplay between autophagy and enterovirus replication is dynamic, selective and sequential. This model illustrates how remodeled cytoplasmic membranes act as a platform for viral RNA replication and as a production line for virion assembly. 1) Capsid proteins, produced as part of the membrane-associated viral polyprotein, assemble on the replication membrane to the point of halfcapsid intermediate. The antiviral drug Hydantoin leads to premature capsid release from membranes. Away from the replication membrane, capsids cannot be loaded with RNA. 2) The assembly pauses at the long-lived half-capsid intermediate that carries out the "late proofreading" resulting in exclusive incorporation of newly synthesized membrane-associated viral RNA (Nugent et al., 1999). The inhibition of VPS34 stalls the assembly at the half-capsid checkpoint. 3) RNA-loading of the capsid leads to the formation of complete virions tethered to the replication membrane. 4) Phagophores selectively package RNA-loaded virions while excluding empty capsids. The virion-containing class of phagophores is distinct from a second class of phagophores containing bundles of protein filaments. 5) A balance between ULK1-induced canonical autophagy and virus-induced proviral autophagy regulates the level of virion production. Inhibition of remaining ULK1 activity by MRT68921 further increases virion production. 